\title{
Mars Thermosphere as seen in MAVEN Accelerometer Data
}

\section{R. W. Zurek ${ }^{1}$, R. A. Tolson ${ }^{2}$, S. W. Bougher ${ }^{3}$, R. A. Lugo ${ }^{4}$, D. T. Baird ${ }^{5}$, J. M. Bell ${ }^{2}$ and B. M. Jakosky ${ }^{6}$}

${ }^{1}$ Jet Propulsion Laboratory, Pasadena, California, USA, ${ }^{2}$ National Institute of Aerospace, Hampton, Virginia, USA, ${ }^{3}$ University of Michigan, Ann Arbor, Michigan, USA, ${ }^{4}$ Analytical Mechanics Associates, Inc., Hampton, Virginia, USA, ${ }^{5}$ NASA Johnson Space Flight Center, Houston, Texas, USA, ${ }^{6}$ LASP, U. of Colorado, Boulder, Colorado, USA

Corresponding author: Richard Zurek (richard.w.zurek@jpl.nasa.gov)

(c) Copyright: All rights reserved.

Key Points:

- MAVEN accelerometer data fill major gaps in space-time coverage of Mars in situ measurements of thermospheric bulk densities.

- Comparisons with models revealed the largest differences in the lower thermosphere $(120-160 \mathrm{~km})$ near the terminators, especially pre-dawn.

- Density variations are largest at the lowest (and coldest) altitudes, above the equator at midnight and over the pre-dawn mid-latitudes.

Headings: 1. Introduction; 2. MAVEN Orbiter Periapsis Geometry; 3. Accelerometer Density Profiles; 4. Parametric ACC-Fits to the Density Profiles; 5. MAVEN Deep Dip Campaigns; 6. Comparisons of MAVEN Accelerometer Data with M-GITM Simulations; 7. Summary

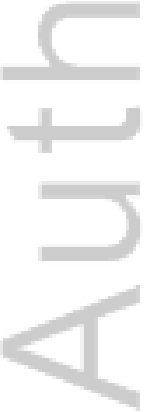

This is the author manuscript accepted for publication and has undergone full peer review but has not been through the copyediting, typesetting, pagination and proofreading process, which may lead to differences between this version and the Version of Record. Please cite this article as doi: 10.1002/2016JA023641

This article is protected by copyright. All rights reserved. 


\begin{abstract}
The Mars thermosphere (above approximately $120 \mathrm{~km}$ ) has been probed in situ for one Mars year using accelerometers onboard the Mars Atmosphere and Volatile Evolution (MAVEN) spacecraft. This region is affected by radiation and energy deposition from the Sun and by energy and momentum from the lower atmosphere. Densities derived from measurements made during the nominal science orbits (periapsis $>140 \mathrm{~km}$ ) show consistent trends with solar zenith angle and Sun-Mars distance, reflecting direct and indirect heating of the thermosphere, although orbit-to-orbit variability is still significant. The six Deep Dip campaigns that MAVEN has conducted (with periapsis dropping below $\sim 135 \mathrm{~km}$ ) significantly extend the vertical profiles of the densities derived from accelerometer data. These show complex structure and high variability, both dependent on season, local time, location, and lower atmosphere activity, including dust storms and wave propagation from a dynamic lower atmosphere. In particular, the terminators are a region of convoluted structure and high variability, which may be greatest in the post mid-night, pre-dawn hours of the sol. This space-time regime was not sampled by previous orbiters at Mars. While initial comparisons with thermospheric general circulation modes show broad areas of agreement, these terminator transition regions are not simulated well by current models. Judicious choice of the timing of these Deep Dip campaigns during the remaining MAVEN mission, as periapsis continues to precess through local time, latitude, and longitude in both hemispheres and in different seasons, should help clarify the processes at work in this complicated region.
\end{abstract}




\section{Introduction}

The thermosphere of Mars, as for other planetary atmospheres, is the transition region from a well-mixed lower atmosphere to regions where gases diffusively separate and are lost to space. The structure and circulation of this region is driven both by energy and momentum fluxes from the lower atmosphere and by extreme ultraviolet (EUV) radiation, solar energetic particle and solar wind influx from above. For Mars, this occurs in the presence of a globally weak magnetic field. The resulting domain has been a challenge to observe and to simulate numerically.

The Mars Atmosphere and Volatile Evolution (MAVEN) mission seeks to understand both the drivers and the subsequent responses of the Martian upper atmosphere in order to understand quantitatively the current mechanisms of escape and their possible contributions to the historic evolution of this atmosphere. Observations of the bulk atmospheric density in the thermosphere help define the spatial and temporal variation of atmospheric structure and the underlying chemical-radiative-dynamical processes at work. Densities have been derived for the upper atmosphere by remote sensing (e.g., Forget et al., 2009; McDunn et al., 2010), but here we focus on in situ measurements of the thermospheric bulk density above $120 \mathrm{~km}$. In situ measurement by accelerometers onboard spacecraft passing through the atmosphere are one means of determining this bulk density structure. Such in situ bulk measurements have been carried out previously as Mars spacecraft have transited to the surface (e.g., Viking, Seiff and Kirk, 1977) or, more extensively, as recent orbiters have aerobraked in the Martian atmosphere while establishing their primary science orbits in a fuel-efficient way. Such aerobraking campaigns were carried out on Mars Global Surveyor (MGS) in 1997-99, Mars Odyssey (ODY) in 2001-02, and Mars Reconnaissance Orbiter (MRO) in 2006 (see, e.g., Tolson et al., 2006; see Fig. 1). (The ESA ExoMars Trace Gas Orbiter, which arrived at Mars in September 2016, plans to aerobrake throughout much of 2017.)

Spacecraft accelerometer measurements taken during aerobraking by these missions have revealed phenomena as diverse as a "blooming" of density at a given altitude in response to a regional dust storm in the lower atmosphere (MGS, Keating et al., 1998), a high-altitude winter polar warming (ODY, Keating et al., 2003; Bougher et al., 2006), stationary planetary waves at low latitudes, gravity waves and tides (e.g., Forbes et al., 2002; Fritts et al., 2006; Tolson et al., 2006). Even so, these aero-maneuver phases have been relatively short and the time-space domain sampled has been relatively limited compared to the scales of variation.

MAVEN entered Mars orbit in September of 2014 and has added in a major way to observations of thermospheric gas densities. MAVEN began its primary science mission in November of 2014 without aerobraking, but did lower its periapsis to an altitude $\sim 155 \mathrm{~km}$ (apoapsis remains $>6000 \mathrm{~km}$ ). During its one-year primary science phase and a nearly equally long first extended mission, MAVEN has observed thermospheric densities along trajectories whose periapsis has been targeted to a density corridor of $0.05-0.15 \mathrm{~kg} / \mathrm{km}^{3}$ on nearly 4000 Nominal Science (NS) orbits. In six carefully planned Deep Dip (DD) campaigns, the MAVEN 
team has lowered the spacecraft periapsis to even higher densities (lower altitudes), targeted to a control corridor of $2.0-3.5 \mathrm{~kg} / \mathrm{km}^{3}$ with each campaign lasting a week or more [Jakosky et al., this issue, and references therein].

Figure 1 shows how these new MAVEN data complement the time-space coverage of measurements by earlier missions during their aerobraking campaigns. It is important to note that the periapsis altitudes of these missions were not same. In the nominal MAVEN science orbits, the altitude at spacecraft periapsis was above $140 \mathrm{~km}$. However, during the six Deep Dip campaigns, periapsis was at significantly lower altitudes $(115-135 \mathrm{~km}$; see Table 1). Periapsis altitudes for the earlier aerobraking missions could be more than $15 \mathrm{~km}$ lower than the lowest MAVEN DD altitudes and the densities there were correspondingly higher. The MAVEN coverage is much more systematic with respect to local solar time (LST) coverage, as those previous missions were aerobraking to achieve mid-afternoon, sun-fixed orbits for their prime missions. MAVEN also covers a full Mars year, as indicated in the $\mathrm{L}_{\mathrm{s}}$ plots, where the areocentric longitude of the $\operatorname{Sun}, \mathrm{L}_{\mathrm{s}}$, is used as a slightly nonlinear measure of the Mars year $\left(\mathrm{L}_{\mathrm{s}}\right.$ $=0^{\circ}, 90^{\circ}, 180^{\circ}$ and $270^{\circ}$ mark the beginning of northern spring, summer, fall and winter, respectively). (The ESA Mars Express orbiter also has an orbit that precesses in local time but, like MAVEN, it did not aerobrake; unlike MAVEN, the Mars Express periapsis does not dip much below $250 \mathrm{~km}$.)

\section{Insert Figure 1}

Deriving density in situ in the upper atmosphere can also be done by interpreting the MAVEN delta velocity (DV) experienced by the spacecraft during an orbit [Demcak et al., 2016] and by in situ mass spectrometry, which can separate gases of various molecular weight [Neutral Gas and Ion Mass Spectrometer (NGIMS), Mahaffy et al., 2015a,b]. NGIMS data have supported various analyses [e.g., Withers et al., 2015; Yigit et al., 2015; Bougher et al., 2016] and efforts to compare with the MAVEN accelerometer data are ongoing (see below). We report here on derivations using the MAVEN spacecraft onboard accelerometers described in Zurek et al., 2015. The advantage of the accelerometer data over the tracking data is that densities can be derived along the spacecraft trajectory through the atmosphere, as opposed to interpreting the integrated value obtained by tracking the spacecraft. The accelerometer trace thus enables an estimate of the density scale height at various altitudes, as well as density. The use of different approaches, each with their individual limitations and uncertainties, ultimately provide a more robust picture of atmosphere structure against which to compare and improve models of the thermosphere.

Section 2 gives pertinent information on the MAVEN periapsis trace through the spacetime geometry of the MAVEN primary mission and of its first extended mission (EM1), a period starting November 2014 and ending October 1, 2016 and spanning one Mars year. Section 3 describes representative profiles of density derived from accelerations measured as the spacecraft passed through periapsis in the atmosphere (referred to hereafter as the aeropass). 
Section 4 describes a 4-parameter fit to these profiles (hereafter referenced as the ACCfits), yielding estimates of periapsis density, scale height, and along-path gradients in both density and scale height. These ACC-fits enable characterization of the large-scale thermospheric structure and its variation in local time and space at the expense of small-scale or rapidly changing phenomena that are not adequately sampled by the MAVEN orbit. This approach is also more reliable for the nominal science orbits where the accelerometer data have a lower signal-to-noise ratio (SNR) in the less dense half of the density corridor. Although the ACC parameters are derived for both for NS and DD orbits, confidence in the ACC profile is greater for the higher densities (see Section 3). Section 5 focuses on analysis of ACC-fits derived from data taken during the six DD campaigns, and Section 6 compares those DD results with simulations by the Mars-Global Ionosphere-Thermosphere Model (M-GITM) [Bougher et al. 2015a].

\section{The MAVEN Orbiter Periapsis Geometry}

Since the start of the primary science phase, the MAVEN periapsis altitude has varied from $\sim 140$ to $\sim 180 \mathrm{~km}$ for the nominal science (NS) orbits, as the spacecraft team strove to keep the MAVEN periapsis densities in a "corridor" between 0.05 to $0.15 \mathrm{~kg} / \mathrm{km}^{3}$. This density corridor provided a safe environment for the spacecraft and science instrument operations. Note that altitudes are referenced to the oblate spheroid used to navigate the spacecraft, with its equatorial radius of $3396.19 \mathrm{~km}$ and a flattening ratio of $\sim 5.886 \mathrm{E}-03$ [Seidelmann, 2002].

\section{Insert Table 1}

Density corridor control was achieved by performing small propulsive orbit trim maneuvers (OTM) that lowered or raised periapsis; these also compensated for the effects of atmospheric drag caused by the low periapsis altitudes $(<200 \mathrm{~km})$. The resulting altitudes are shown in Figure 2. Orbit trim maneuvers produce the noticeable altitude changes; these are conducted when the densities trend outside the corridor, either to higher or lower values, and are compensated by up or down maneuvers in altitude to lower or raise densities, respectively. The DD targeted density corridor was $2-3.5 \mathrm{~kg} / \mathrm{km}^{3}$ (Table 1 ), a regime where the atmosphere is still relatively well-mixed. DD campaigns typically lasted one week with DD corridor altitudes ranging from 115 to $135 \mathrm{~km}$, as seen in Figure 2. Intermediate altitudes (e.g., most NS points below $140 \mathrm{~km}$ in Fig. 2) between the NS and DD orbits occurred where the spacecraft stepped into (down in altitude) or out of (up in altitude) the DD target density corridor. Note that the altitude of a constant density level-and thus the altitudes of the target NS and DD density corridor-changes with season and, given the non-spherical shape of Mars, with latitude. Further description of the navigation and flight processes of corridor control and observing attitude of the spacecraft are given in Demcak et al. (2016).

\section{Insert Figure 2}


The MAVEN orbit is inclined at $\sim 75^{\circ}$. As seen in the right panel of Figure 1 , the MAVEN periapsis moved from northern latitudes near $75^{\circ}$ towards and across the equator to southern latitudes near $75^{\circ}$ during the one-year of the primary mission, then back to the northern limit and south again, reaching southern mid-latitudes by October 1, 2016, the end of the first extended mission. Four DD campaigns were conducted during the primary mission and two in the extended mission (red symbols and vertical lines in Fig. 2).

Given a nominal 4.5-hour orbital period, MAVEN samples five to six longitudes spread around the planet each Mars day (sol). This north-south variation and progression through local time will continue into the second two-year extended mission that began October 1, 2016. The trace of the MAVEN periapsis by orbit during the primary and first extended mission is shown in Figure 3 as a function of true local solar time (TLST), solar zenith angle (SZA $=0^{\circ}$ is overhead Sun and local noon), and areocentric longitude $\mathrm{L}_{\mathrm{s}}$. The minimum Sun-Mars distance (Mars perihelion) occurs at $\mathrm{L}_{\mathrm{s}} \sim 251^{\circ}$. Note that the MAVEN orbit precesses through $\sim 3.5$ diurnal cycles per Mars year, providing adequate sampling/separation of the diurnal/seasonal cycles.

\section{Insert Figure 3}

\section{Accelerometer Density Profiles}

Accelerometers sense atmospheric drag on the spacecraft, from which density $\rho$ along the flight path may be derived by the traditional relationship:

121* MERGEFORMAT ()

where the $z$-axis is assumed to point along the direction of flight, $A$ is the reference frontal area of the spacecraft orthogonal to the $z$-axis, $M$ is the mass of the spacecraft, $V$ is the speed relative to the atmosphere, $C_{z}$ is the aerodynamic force coefficient along the $\mathrm{z}$-axis of the spacecraft and $a_{z}$ is the acceleration of the spacecraft center of mass due to aerodynamic forces along the $z$-axis. Details of this basic analysis of the accelerometer data can be found in Tolson et al. (2006) and Zurek et al. (2015).

If the atmosphere were isothermal and hydrostatic, the density profile near periapsis is described by:

341* MERGEFORMAT () 
where is the density at periapsis, $h$ is the altitude above periapsis, and is the density scale height. In the idealized case of constant $H_{s}$, the inbound and outbound density values are identical at the same altitude, and the density profile as the spacecraft passes through periapsis (which we shall refer to as the aeropass) follows a Gaussian form [King-Hele, 1964].

\section{Insert Figure 4}

Figure 4 shows the altitude profiles (dashed black curves) and smoothed accelerometerderived density profiles (blue) generated using a 99-point running mean on the $1 \mathrm{~Hz}$ accelerometer data. This smoothing yields a 1-sigma noise level of $\sim 0.02 \mathrm{~kg} / \mathrm{km}^{3}$ based on accelerometer performance (Zurek et al., 2015) and provides robust results when the peak densities are greater than $\sim 0.1 \mathrm{~kg} / \mathrm{km}^{3}$. If the periapsis densities are lower than that value, the profiles may have "wavy" structure that we interpret to be noise (e.g., Fig. 4d).

It is important to remember that every aeropass is a two-dimensional pass through the atmosphere, mixing vertical and horizontal variation. Thus, the time axis of the plots in Fig. 4 represents principally spatial variation. The spacecraft velocity at periapsis is $\sim 4.2 \mathrm{~km} / \mathrm{s}$, so 200 seconds of flight time (marked on the $\mathrm{x}$-axis) corresponds to $\sim 840 \mathrm{~km}$. Data are taken every second, while a 99-point running mean is used to smooth the data for the ACC-fits. This reduces the along-track spatial resolutions to several tens of $\mathrm{km}$ in the horizontal and a few $\mathrm{km}$ in the vertical, though the angle between vertical and horizontal varies with altitude, of course.

Non-random errors can be introduced in the conversion of accelerations to density by uncertainties in spacecraft attitude during the aeropass and in the associated aerodynamic error coefficients (Eq. 1; Zurek et al., 2015; Tolson et al., 2017). Comparisons with densities from slightly varying spacecraft attitudes during different aeropasses indicates accuracies for profiles derived here within a few per cent. As explained in Section 6, comparisons with the integrated changes in spacecraft velocity during the aeropass derived from tracking data (delta-V) indicate systematic differences of less than $10 \%$.

The profiles selected for Figure 4 vary in longitude, latitude, local time, and season. The DD density profiles (for orbits P01060, P01515, P03552, P03580) generally follow the Gaussian shape described by Eq. (2). In some cases, such as in Figs. $4 c$ and $4 d$, the maximum density occurs slightly after periapsis. Of particular interest are the scale heights near periapsis; note the cold regions indicated in Fig. 4e, where a sharp "beak" in density is seen at the lowest altitudes both before and after periapsis.

Higher frequency variations sometimes appear in the profiles and may represent real density variation. However, as noted above, when the peak density is low, as seen in Fig. 4d, these fluctuations are likely non-physical and reflect the low SNR of the accelerometers. Of course, the atmosphere is typically considerably more complex than the idealized isothermal and hydrostatic case, especially given the two-dimensional nature of the aeropass trajectory. Fig 4b, a DD orbit, exhibits structure near periapsis that the idealized model is unable to capture. These 
large-scale variations in the derived density with altitude or between the inbound and outbound legs are likely real, especially when the peak densities are greater than $0.1 \mathrm{~kg} / \mathrm{km}^{3}$. To capture these features, the four-parameter ACC-fits shown in Fig. 4 and described in the next section were generated to provide a better representation of the density variation.

\section{Parametric ACC-Fits to the Density Profiles}

To capture the basic structure of the density field, the density profiles (represented by the blue profiles in Fig. 4) have been fit (red curves in Fig. 4) using four adjustable parameters: 1) periapsis density , 2) along track density gradient at the periapsis altitude, 3) density scale height near periapsis , and 4) along track scale height gradient at the periapsis altitude. The ACC profile density at any altitude $h$ and time $t$ along the aeropass ( $t=0$ at periapsis) is:

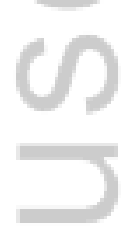

$561^{*}$ MERGEFORMAT ()

Assuming that the contributions from the gradient terms are small compared to the nominal values, the expression may be approximated to first order by:

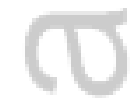

or, in terms of the four parameters $(\mathrm{a}, \mathrm{b}, \mathrm{c}, \mathrm{d})$ in the least squares solution,

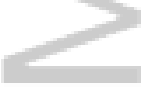

Note that in the vicinity of periapsis, $h$ is proportional to $t^{2}$, so this expansion is essentially the third order Taylor series for in time and is therefore unsuitable for extrapolation.

As shown in Fig. 4, the ACC profile fits (shown in red) capture the density structure in the vicinity of periapsis. Cases were chosen in Fig. 4 to exhibit both good and poor ACC profile fits to illustrate some of the difficulties in capturing certain atmospheric phenomena. For example, Fig. 4a and Fig. 4f are cases in which the model is able to capture the density profile extremely well. Fig. $4 c$ is well represented by just the $\mathrm{H}_{\mathrm{s}}$ gradient term in Eq. (4), while the profile in Fig. $4 \mathrm{~b}$ requires both gradient terms. Nevertheless, the gradient terms are not interpreted as real properties of the atmosphere, but rather indicators that the atmosphere is not locally isothermal and hydrostatic. Real deviations, such as vertical temperature or molecular weight variations, gravity waves, and thermal tides, are absorbed in these terms. Also real are the differences evident between ingress and egress densities at a given altitude and also different 
scale heights, derived here for $10 \mathrm{~km}$ segments of the profile, illustrated in Fig. 4 (right-hand panels). The 150-km reference level was chosen to facilitate comparisons with earlier orbiter missions.

The four parameters of the ACC fits are shown in Fig. 5 in terms of density at periapsis, density scale height at periapsis, and the gradients of and $\ln \mathrm{H}_{\mathrm{s}}$ with time from periapsis. Except for the first few hundred orbits, when periapsis was being lowered into the NS corridor (Fig. 2), all these orbits are either in or near to the NS or DD corridors. As might be expected, the largest $\mathrm{H}_{\mathrm{s}}$, which is an indicator of atmospheric temperature, occurs during daylight hours and drops dramatically at sunset (also Fig. 6). Typically, the temperature increases with height in the thermosphere and so the $\mathrm{H}_{\mathrm{s}}$ variation in Fig. 5 is also highly correlated with altitude (compare with Fig. 2). These competing effects are discussed in more detail below.

The mean along-track density gradient also shows temporal variability. This gradient is directly related to the deviation of the maximum density from the time of periapsis. A systematic trend in the highly inclined along-track $\mathrm{H}_{\mathrm{s}}$ gradient might be expected to capture the natural latitudinal trends in temperature and in molecular weight, but this signal appears to have a constant mean near zero. Correlations of both mean values and deviations from the mean are of interest for atmospheric modeling and atmospheric flight.

To provide more robust quantitative results, the orbits were divided into contiguous bins. Six of these bins contained orbits from individual DD campaigns. Seventy-one additional bins were chosen to include 30 to 70 contiguous orbits between OTMs. This assured that each bin contained orbits at similar altitudes, latitudes, TLST, and SZA. The mean and standard deviation for each of the 77 bins were calculated for the ACC-fit parameters.

\section{Insert Figure 5}

\section{Insert Figure 6}

Figure 6 illustrates the orbit-to-orbit variation for binned values of the ACC fit to $\log$ density and of the along-track gradients of density and scale height, together with the binned values of $\mathrm{H}_{\mathrm{s}}$ itself. Whether the binned periapses were in daylight or dark is also indicated. Because of the precession of the MAVEN orbit, the sequence of time of day versus orbit number is reversed: Periapsis moved earlier from noon to sunrise to midnight to sunset (Fig 3). Four of the six DD campaigns were deliberately chosen to occur near sunrise or sunset, as the twilight regions were relatively unexplored and the thermospheric structure there is quite complex, posing significant challenges to model simulation (see Section 6). In contrast, DD2 was chosen to occur near noon and DD6 near midnight (Fig. 3). There is clearly a high correlation between a day or night bin and the orbit-to-orbit variability in density and the magnitude of both alongtrack gradients. All of this strongly suggests that dynamics are playing a very significant and perhaps dominant role at night. Except for $\mathrm{H}_{\mathrm{s}}$, comparisons between DD and NS data do not suggest a persistent dependence on altitude. At DD altitudes (where the atmosphere is well 
mixed), $\mathrm{H}_{\mathrm{s}}$ is an indicator of atmospheric temperature, with lower temperatures than at NS altitudes. For DD2 the nearby NS orbits have $\mathrm{H}_{\mathrm{s}}$ values nearly twice the DD2 value, suggesting a large vertical temperature contrast between the DD and NS altitudes, separated by $\sim 50 \mathrm{~km}$. DD6 on the other hand has a much smaller ratio suggesting a much smaller vertical temperature contrast (over $\sim 25 \mathrm{~km}$ ) near the anti-solar point, although this is one of the colder regions sampled.

\section{Insert Figure 7}

In a different approach to isolating long-term trends in density, the ACC-fit periapsis densities, which occur at a wide range of altitudes (Fig. 1), are mapped to a reference altitude of $150 \mathrm{~km}$, commonly used as a reference by previous aerobraking missions. Unfortunately, the localized scale heights derived from the model fits (Eq. 3 and Fig. 4) are generally not representative of the vertical differences between the periapsis altitude and the reference altitude. From Fig. 4 it is seen that inbound and outbound scale heights - as well as density —are often quite different due to the horizontal separation of the aeropass trajectory and the frequent appearance of vertically propagating waves (e.g., Fig. 4f). Furthermore, some periapses occur at altitudes well above $150 \mathrm{~km}$.

Consequently, the extrapolation is performed using values of effective scale height from the Mars-GRAM model [Justus, 2006] used by the spacecraft navigation team in planning OTMs [Demcak et al., 2016]. The extrapolated densities are then averaged over 11 contiguous orbits to provide more robust values, particularly for the lower density NS periapses. These are shown in the top panel of Fig. 7. While there is considerable scatter, local time and seasonal variations are apparent, as shown by a parametric fit to the solar zenith angle (SZA) and the inverse square of the Sun-Mars distance $\mathrm{R}_{\mathrm{SM}}$ [astronomical units, $\mathrm{AU}$ ]:

$$
\operatorname{Ln}\left(\rho\left[\mathrm{kg} / \mathrm{km}^{3}\right]\right)=-5.45+(8.22+2.63 * \cos (\mathrm{SZA})) / \mathrm{R}_{\mathrm{SM}}{ }^{2}
$$

Both the $\cos (\mathrm{SZA}) / \mathrm{R}_{\mathrm{SM}}{ }^{2}$ and the $\mathrm{R}_{\mathrm{SM}}{ }^{-2}$ modulate solar heating of the Mars atmosphere.

Figure 7 also shows the orbit to orbit variation defined as the 1-sigma deviation from the mean of each set of 11 contiguous orbits (i.e., periapsis longitudes circling the planet nearly twice).

Fitting sigma normalized by the mean $\mu_{11}$ to the SZA (blue line in Fig. 7 bottom panel) yields:

$$
\sigma_{11} / \mu_{11}=0.27-0.1 * \cos (\mathrm{SZA})
$$

Figure 7 shows that the highest variability does occur on the night side of the morning and evening terminators, as was also suggested in Fig. 6. Orbit to orbit variability of density varying from around $15 \%$ to $40 \%$ is consistent with experience from aerobraking missions [e.g. Fritts et al., 2006] and recent NGIMS gravity wave studies [e.g., Yigit et al. 2015].

\section{Insert Figure 8}


The left and middle panels of Fig. 8 show the variation of scale height $\mathrm{H}_{\mathrm{s}}$ with periapsis altitude and solar zenith angle. Recall from Fig. 1 that for the MAVEN orbit altitude and SZA are somewhat correlated: MAVEN strives to keep periapsis in a density corridor which moves in altitude as affected by thermospheric heating and thus SZA. In Fig. 8, it is not surprising to see $\mathrm{H}_{\mathrm{s}}$ increasing with altitude $h$ and $\cos (\mathrm{SZA})$, as that trend in temperature is a defining characteristic of the thermosphere as it is heated by EUV absorption. A simple linear model was fit to the NS orbit data to quantify the relative contribution of periapsis altitude $h_{r}$ above $150 \mathrm{~km}$ and $\cos (\mathrm{SZA})$ to the changes in $\mathrm{H}_{\mathrm{s}}$ within the NS density corridor:

$$
\mathrm{H}_{\mathrm{s}}(\mathrm{km})=10.2+2.3 * \cos (\mathrm{SZA})+0.1 * h_{r}
$$

The third panel in Fig. 8 shows the residual between the data values and the model values. No obvious trends remain in the residuals, which have a mean of zero and a standard deviation of $0.77 \mathrm{~km}$. Eq. (8) suggests that, for $\mathrm{NS}$ orbits, $\mathrm{H}_{\mathrm{s}}$ will increase by $4.6 \mathrm{~km}$ from the anti-solar point to the sub-solar point and by $1 \mathrm{~km}$ per $10 \mathrm{~km}$ of altitude. Warmer daytime temperatures are also expected, but note the large variability in scale height on the night-side of the terminator. This indicates that temperature as well as density has high variability there and likely reflects effects of the cross-terminator circulations.

Even though there are only 6 DD bins, the data suggest that SZA is less significant in the DD corridor by about a factor of two, most likely because more of the EUV has been absorbed in the atmosphere above the DD corridor and the lower altitudes are also more affected by the dynamical forcing from below. Additional DD campaigns during the extended missions may provide additional support for this conjecture.

\section{MAVEN Deep Dip Campaigns}

Table 2 gives start and end orbit numbers and dates of the six DD campaigns that MAVEN has conducted as of October 2016. These do not include those orbits where the spacecraft was stepping down or up from the DD corridor. Representative $\mathrm{L}_{\mathrm{s}}$, solar zenith angle, local true solar time (LTST; hrs = 1/24 Mars sol; noon = $12 \mathrm{hrs)}$ ) and periapsis latitudes are shown in Table 3, with a brief description of the environment (e.g., midnight at the equator). These DD campaigns were spread unevenly over one Mars year with some emphasis on sampling the terminator portions of the local time variation, as these were regions of high variability and of complex interplay between dynamics and radiation. Six DD campaigns are not enough to sample the many possible combinations of season, time-of-day, and location on the planet, but they do fill voids in the earlier coverage from aerobraking Mars orbiters (Fig. 1). In particular, DD2 (near noon) and DD6 (near midnight) sampled low latitudes near the equinoxes, while DD1 and DD5 sampled the dusk and dawn terminators, respectively.

\section{Insert Table 2}




\section{Insert Table 3}

\section{Insert Figure 9}

The different periapsis altitudes sampled during the DD campaigns are shown in Figure 9. Recall that since the targeted density corridor was the same for all six campaigns, these altitude differences partially reflect seasonal trends of solar heating at different latitudes. DD1-2 were both conducted during/near the perihelion season when Mars is closest to the sun and the lower atmosphere had expanded due to the greater solar heating. Also, the southern spring and summer are also the seasons when vast dust hazes can be produced from regional dust storms, and the direct heating of the dusty atmosphere can further raise the altitude of a constant density surface.

Finally, the local time and latitude also play a role, with the diurnal variations of temperature being large on Mars and able to propagate their influence vertically. The dusty atmosphere and near-zero solar zenith angle (combining effects of local time and latitude) appear to be responsible for similar density at higher altitudes for DD2 compared with DD1, and for the two populations of altitudes during DD2. DD3 and DD4 are closest to Northern Spring equinox, while DD6 is quite close to Northern Fall equinox. These orbits reveal similar densities at comparable altitudes. DD5 is remarkable for its low periapsis altitudes and both DD5 and DD6 have large variations at these lowest altitudes, suggesting the high variability of the lower thermosphere during the midnight to pre-dawn hours.

Several of the DD5 profiles exhibited a sharp "beak" near periapsis, indicating cold temperatures (Fig. 4e, orbit 3552). Indeed, these DD5 orbits may have grazed the top of a cold mesopause region at altitudes observed by Mars Express SPICAM measurements [Forget et al., 2009; McDunn et al., 2010]. Unfortunately, the MAVEN coverage is inadequate to make a more definitive statement.

\section{Comparisons of MAVEN Accelerometer Data with M-GITM Simulations}

The large periapsis densities encountered during DD campaigns yield accelerometer (ACC) values with very good SNR. Before comparing the DD profiles to model simulations, it is important to determine if there are any systematic errors that could bias such comparisons. Figure 10 compares the total delta- $\mathrm{V}$ derived independently from navigational analysis of the spacecraft tracking data and recorded in the spacecraft Orbit Propagation and Timing Geometry (OPTG) files [Demcak et al., 2016] and from the accelerometer analysis [Tolson et al., 2017 and this paper]. As shown in the bottom panel of Fig. 10, the comparison is very good with differences of a few per cent at most. This gives us confidence that for all the DD campaigns systematic errors are small and therefore do not enter significantly into comparisons with model simulations or with the in situ data from the NGIMS experiment. The latter are still being analyzed and will be the subject of a later ACC-NGIMS mass density comparison paper. Here we focus on comparisons of the ACC densities with model simulations. 


\section{Insert Figure 10}

\section{Atmospheric Model Description}

The Mars Global Ionosphere-Thermosphere Model (M-GITM) combines the terrestrial GITM framework [Ridley et al., 2006] with Mars fundamental physical parameters, ion-neutral chemistry, and key radiative processes in order to capture the basic observed features of the thermal, compositional, and dynamical structure of the Mars atmosphere from the ground to $\sim 250 \mathrm{~km}$ [Bougher et al., 2015a]. M-GITM simulates the conditions of the Martian atmosphere all the way to the surface, with an emphasis on upper atmosphere processes. Simulated threedimensional upper atmosphere $(80-250 \mathrm{~km})$ fields include neutral temperatures, densities (e.g. $\mathrm{CO}_{2}, \mathrm{CO}, \mathrm{O}, \mathrm{N}_{2}, \mathrm{O}_{2}, \mathrm{He}$ ), winds (zonal, meridional, vertical), and photochemical ions (e.g. O+, $\mathrm{O}_{2}+, \mathrm{CO}_{2}+, \mathrm{N}_{2}+$ and $\mathrm{NO}+$ ). Simulations spanning the full range of applications of the current $\mathrm{M}-$ GITM code, including 12 model runs spanning various solar cycle (minimum, moderate, and maximum) and seasonal $\left(\mathrm{L}_{\mathrm{s}}=0,90,180,270^{\circ}\right)$ conditions, have been completed and the results are described in a comprehensive initial paper [Bougher et al., 2015a].

The M-GITM code produces outputs that are subsequently organized and gathered to create large 3-dimensional datacubes that can be used for comparison with aeropass density profiles. Archived simulation cases (all conducted prior to MAVEN) are selected for study that correspond most closely to the solar (F10.7-cm index rotated to Mars) and seasonal $\left(\mathrm{L}_{\mathrm{s}}\right)$ conditions of the MAVEN Deep Dip campaigns 1-6. Software is then utilized to extract MGITM simulated mass densities along the appropriate spacecraft trajectory paths (below 180 $\mathrm{km}$ ) for each orbit contained in these 6-Deep Dips campaign periods. This was done at a common interval of $2 \mathrm{~km}$, which is limited by the M-GITM code itself. Both inbound (ingress) and outbound (egress) orbit legs are constructed separately, yielding a suite of mass density profiles for each campaign period that are subsequently averaged together.

MAVEN ACC datasets and corresponding M-GITM mass density outputs for each of the Deep Dip campaigns were organized as follows for detailed comparisons. First, the 99-sec running mean datasets described earlier were used. In addition, both the datasets and M-GITM outputs were binned in altitude with a common resolution $(2.0 \mathrm{~km})$ that approximates the resolution of the M-GITM model. Finally, 1-sigma variability at these regular altitude levels spanning all orbits during each campaign is also calculated for examination. These actions enable a more appropriate and complete comparison of datasets and model outputs along the orbit tracks for each of these Deep Dip campaigns.

Note that these simulations, based on model runs all computed before MAVEN entered Mars orbit, do not take into account the actual weather events such as the large regional dust storms that occurred during southern spring and summer.

Comparisons between M-GITM Simulations and NGIMS Data

This article is protected by copyright. All rights reserved. 
The M-GITM physics, chemistry, and dynamical formulations are the most complete for the upper atmosphere, and therefore MAVEN data-model comparisons have largely focused on this region above $\sim 115 \mathrm{~km}$. At this point, M-GITM simulations have been compared with NGIMS measurements obtained during its first year of operations during four Deep Dip campaigns [Bougher et al., 2015b; Bougher, 2015c]. In particular, DD2 temperatures and key neutral densities have been compared with corresponding M-GITM fields extracted along DD2 orbit trajectories on the dayside near the equator [Bougher et al., 2015b]; a good match of key neutral densities and temperatures is revealed at these low solar zenith angles, close to the subsolar point. In addition, the Martian seasonal trend of dayside thermospheric temperatures derived from NGIMS densities was compared to M-GITM predictions; perihelion to aphelion measured temperature variations were shown to match M-GITM predictions quite well [Bougher et al., 2016, this issue].

\section{Comparisons between M-GITM Simulations and Accelerometer Data}

Figure 11 illustrates ingress and Figure 12 presents egress mean mass density profiles (and corresponding 1-sigma variability bars) for Deep Dips 1-6. The averaged local solar time (LST) at periapsis over each campaign is also given for each Deep Dip. It is evident that evening terminator (DD1), near noon (DD2), deep nightside (DD3), high southern latitude (DD4), morning terminator (DD5), and near midnight (DD6) conditions are sampled during the campaigns conducted thus far. Corresponding M-GTIM campaign averaged mass density profiles are plotted as well for the same solar and seasonal conditions. The 1-sigma variability bars on the model results now correspond to longitude variations throughout a simulated model day for the otherwise identical MAVEN trajectory paths (including the LST, latitude, altitude variations).

For the ingress portion of these campaigns (Figure 11), the best ACC vs M-GITM model comparisons are obtained for the DD2 campaign, at low solar zenith angle (SZA). Here, the maximum discrepancy is not more than $\sim 40-50 \%$ near 130 and $170 \mathrm{~km}$. This good match of MGITM model densities to the accelerometer densities is consistent with the corresponding close match of NGIMS derived temperatures and M-GITM temperatures for this same DD2 campaign [Bougher et al. 2015b,c; Bougher et al., 2016 this issue]. These studies together imply that the M-GITM code reasonably captures the low SZA solar driven thermal and corresponding mass density structure of the Mars dayside thermosphere. This further suggests that the underlying MGITM thermal balances, basic photo-chemistry and large scale dynamics are reasonably correct at low SZAs. For DD1 (evening terminator), the data-model discrepancies increase to a factor of 1.6-2.0, with the M-GITM code predicting larger densities. This may result from warmer model temperatures than the Martian thermosphere at this location; i.e., the M-GITM may not properly capture the sharp horizontal temperature and density gradients across the evening terminator.

The rest of the DD campaign comparisons at large SZAs (i.e. at high latitude, near midnight, and near dawn) reveal larger differences with the M-GITM model. The data-model 
discrepancies are largest for DD3 (factors of 4.0 to 5.0) and DD5 (factor of 6.0), while smaller for DD4 (factor of 3.0 ). In each of these cases, the implication is that the primarily solar driven M-GITM does not capture the high SZA behavior of the thermospheric density and temperature structure. This may be the result of thus far neglecting gravity wave impacts within M-GITM, including momentum and energy deposition that other model simulations suggest may be important at higher latitudes, where polar jets are strong, and onto the nightside [e.g., Medvedev et al. 2015; England et al. 2016, this issue). This high-latitude forcing can affect even the lowlatitude circulation by continuity. Under such wave forcing, the simulated inter-hemispheric (and day-to-night) thermospheric circulation may be weaker, consistent with cooler nightside temperatures and reduced mass densities [e.g., Lillis et al., 2010]. In addition, incorporation of $\mathrm{CO}_{2}$ cooling requires the feedback of atomic $\mathrm{O}$ and $\mathrm{CO}_{2}$ collisional exchange rates for accurate "dynamical" $\mathrm{CO}_{2}$ cooling rates to be calculated [Lillis et al., 2010; Bougher et al., 2016, this issue]. A comparison of the simulated M-GITM atomic $\mathrm{O}$ abundances with NGIMS measurements on the nightside is therefore warranted. These $\mathrm{O}$ abundances will be the subject of future data-model studies utilizing calibrated NGIMS datasets.

\section{Insert Figure 11}

For the egress portion of these campaigns (Figure 12), the best ACC vs M-GITM model comparisons are also obtained for the DD2 campaign (within 30-50 \%). However, most of the rest of the egress campaigns at high SZAs show an even larger discrepancy (compared to ingress) between data and model predictions at most altitudes. For instance, DD3 (deep nightside) now reveals up to a factor of 20 discrepancy between data and model near $140 \mathrm{~km}$. The spatial sampling provided by the DD3 orbits covers high southern latitudes in the pre-dawn sector (see Table 3). The simulated aeropass spatial (horizontal) variability is large in this predawn sector, making mass density comparisons with NGIMS measurements difficult.

\section{Insert Figure 12}

Lastly, the dusk to dawn terminator asymmetry in the mass densities at thermospheric altitudes is clearly seen by examining DD1 (dusk terminator, perihelion) and DD5 (dawn terminator, near autumnal equinox) mass densities at altitudes $\sim 130$ to $150 \mathrm{~km}$. During ingress, the dusk/dawn ratio is $\sim 5.0$ to $\sim 10.0$ (130 to $140 \mathrm{~km}$ ), while for egress the same ratio is $\sim 3.6$ to $\sim 2.7$ (130 to $150 \mathrm{~km})$. A change in season occurred between DD1 and DD5 sampling periods, and may be another contributor to these changes. Nevertheless, these ratios indicate that the evening terminator exhibits significantly larger mass densities at these altitudes (130 to $150 \mathrm{~km}$ ). This same dusk to dawn trend is also predicted by M-GITM, although to a lesser degree. This asymmetry is also consistent with LPW electron temperatures that appear warmer at the dawn terminator, corresponding to the reduced background atmosphere densities available for collisional cooling of electrons [Andersson et al., 2016]. 


\section{Summary}

Densities derived above $140 \mathrm{~km}$ from MAVEN spacecraft accelerometer measurements taken during nominal science orbits for a full Mars year show systematic trends with season and solar zenith angle, likely reflecting changes in solar EUV heating (Fig. 7). Variation with solar zenith angle reflects both seasonal change of the subsolar point and the latitudinal location of the spacecraft periapsis. There is also correlation at the lower DD altitudes, but it is not as strong, reflecting the greater influence there of lower atmosphere inputs, which may reflect solar heating (at visible wavelengths) more indirectly. Interestingly, the short period variability was similar for both NS and DD orbits during much of the Mars year, although density and its variation were significantly larger for the last two DD campaigns (Fig. 9), conducted just before and after the southern spring equinox when forcing from a dusty lower atmosphere may have been increasing. As expected, scale heights at the lower altitudes of the DD were smaller, reflecting mainly a colder atmosphere as the spacecraft approached the Mars mesopause. Again, the fall equinox temperatures were lowest (Fig. 8). The largest density variations in any of the six DD campaigns were observed (Fig. 9) at the lowest (and coldest, Fig. 6) altitudes, which were encountered during DD5 and DD6. DD5 occurred during the pre-dawn over northern mid-latitudes and also showed a rapid decrease of density with height (i.e., small scale height) near periapsis (Fig. 4e). DD6 occurred during midnight above the equator (at the anti-solar point). This space-time environment was not sampled by earlier aerobraking missions (Fig. 1).

Comparison of the integrated accelerometer data with the delta-V measurements from tracking the spacecraft showed good agreement, indicating that there are no major biases between the two. Thus, the DD density profiles at lower altitudes should be a particularly good standard for comparison with other data. Comparisons of those DD density profiles with the precomputed M-GITM fields showed generally good agreement at low solar zenith angles, but comparisons near the terminators were not as good, with the largest differences in the pre-dawn hours (Figs 11-12). This points to deficiencies in the computed circulation. The absence in the model of gravity wave drag may be a contributor, as well as deficiencies in the computation of collisional exchange and non-LTE radiative cooling by $\mathrm{CO}_{2}$. Both will be investigated. These larger discrepancies were first revealed by the MAVEN observations, as these local times were not well-sampled during earlier aerobraking missions at Mars (Fig. 1).

The six Deep Dip campaigns that MAVEN has conducted thus far, while too few in number to characterize fully the upper thermosphere of Mars, have nonetheless revealed the complex structure of a region affect by radiation and energy deposition from the Sun and by radiative exchange and wave propagation from a dynamic lower atmosphere. Season, local time, position on the planet and weather in the lower atmosphere can all play a role. In particular, the terminators are a region of strong gradients and high variability, which may be greatest in the post mid-night, pre-dawn hours of the sol. The analysis here has focused on the most general features of the density variations; there is much information on atmospheric waves and longitudinal variation that may be gleaned from these data with further analysis. Two Deep Dips 
during the second MAVEN extended mission will test the repeatability (or the inter-annual variability) of data already acquired for similar environmental conditions; currently DD7 would sample the evening terminator at high solar latitudes (similar to DD1) and DD8 would reexamine subsolar conditions (similar to DD2). A third Deep Dip campaign would take advantage of an opportunity to explore the upper atmosphere above strong crustal-magnetic-field locations in the southern hemisphere on the planetary dayside.

\section{Acknowledgments, Samples, and Data}

We thank our colleagues on the MAVEN navigation and NGIMS teams for discussions and suggestions. This work was supported by the MAVEN project and funded by the National Aeronautics and Space Administration (NASA) as part of the Mars Exploration Program. Part of this work was conducted at the Jet Propulsion Laboratory, California Institute of Technology under contract with NASA. Delta-V values were obtained from the spacecraft Orbit Propagation and Timing Geometry (OPTG) files [Demcak et al., 2016]. All MAVEN Accelerometer (ACC) datasets used in this paper are available on the public version of the MAVEN Science Data Center (SDC) website at the University of Colorado/LASP (https://lasp.colorado.edu/maven/sdc/public/) as well as the Planetary Data System (PDS). Likewise, all data-cubes containing the M-GITM simulated mass densities used for comparison with ACC values in this paper are taken from the model archive also found on the MAVEN public website.

\section{References}

Andersson, L., et al. (2016), Diurnal variations in electron temperature in the Mars ionosphere, Geophys. Res. Lett., to be submitted.

Bougher, S. W., D. Pawlowski, J. M. Bell, S. Nelli, T. McDunn, J. R. Murphy, M. Chizek, and A. Ridley (2015a), Mars global ionosphere-thermosphere model: Solar cycle, seasonal, and diurnal variations of the Mars upper atmosphere, J. Geophys. Res., 120, 311-342, doi:10.1002/2014JE004715.

Bougher, S. W., B. M. Jakosky, J. Halekas, J. Grebowsky, J. G. Luhmann, and others (2015b), Early MAVEN dip deep campaign reveals thermosphere and ionosphere variability, Science, 350, 1-7, doi:10.1126/science.aad0459.

Bougher, S. W., J. M. Bell, K. Olsen, K. Roeten, P. R. Mahaffy, M. Elrod, M. Benna, and B. M. Jakosky (2015c), Variability of Mars thermospheric neutral structure from MAVEN deep dip observations: NGIMS comparisons with global models, EOS, 2015, Supplement (74805).

Bougher, S. W., K. J. Roeten, K. Olsen, P. R. Mahaffy, and others (2016). The structure and variability of Mars dayside thermosphere from MAVEN NGIMS and IUVS 
measurements: Seasonal and solar activity trends in scale heights and temperatures, J. Geophys. Res., 121, this issue, doi:10.1002/2016JA023454.

Demcak, S., et al., (2016). MAVEN navigation during the first Mars year of the science mission, AIAA/AAS Astrodynamics Specialist Conference, SPACE Conferences and Exposition, Long Beach, CA, 13-16 September 2016. http://dx.doi.org/10.2514/6.2016-5428

England, S. L., G. Liu, E. Yigit, P. R. Mahaffy, M. Elrod, M. Benna, H. Nakagawa, N. Terada, and B. M. Jakosky (2016), MAVEN NGIMS observations of atmospheric gravity waves in the Martian thermosphere, J. Geophys. Res., 121, doi:10.1002/2016JA023475, this issue.

Forget, F., F. Montmessin, J.-L. Bertaux, F. Gonzalez-Gálindo, S. Lebonnois, E. Quémerais, A. Reberac, E. Dimarellis, and M. A. López-Valverde (2009), Density and temperatures of the upper martian atmosphere measured by stellar occultations with Mars Express SPICAM, J. Geophys. Res., 114, (E01004), doi:10.1029/2008JE003086.

Forbes, J., A. Bridger, S. Bougher, M. Hagan. J. Hollingsworth, G. Keating, J. Murphy, (2002), Non-migrating tides in the thermosphere of Mars. J. Geophys. Res. (2002) doi:10.1029/2001JE001582.

Fritts, D. C., L. Wang, and R. H. Tolson (2006). Mean and gravity wave structures and variability in the Mars upper atmosphere inferred from Mars Global Surveyor and Mars Odyssey aerobraking densities, J. Geophys. Res., 111, (A12304), doi:10.1029/2006JA011897.

Jakosky, B. et al., (2016), The MAVEN mission to Mars at the end of one Mars year of science observations, J. Geophys. Res., 121, this issue.

Justus, C.G., (2006), Aerocapture and validation of Mars-GRAM with TES data, $53^{\text {rd }}$ JANNAF Propulsion Meeting and $2^{\text {nd }}$ Liquid Propulsion Subcommittee and Spacecraft Propulsion Joint Meeting.

G.M. Keating, S.W. Bougher, R.W. Zurek et al. (1998), The st ructure of the upper at mosphere of Mars: in-sit u accelerometer measurements from the Mars Gl obal Surveyor. Science, 279, 1672-1676.

G.M. Keating, M. Theriot, R. Tolson et al. (2003), Brief review on the results obtained with the MGS and Mars Odyssey 2001 accelerometer experiments. in Mars Atmosphere: Model ing and Observations Workshop (13-15 January 2003), Granada, Spain.

King-Hele, D. (1964), Theory of Satellite Orbits in an Atmosphere, Butterworths Mathematical Texts, London. 
Lillis, R. J., S. W. Bougher, F. Gonzalez-Galindo, F. Forget, M. D. Smith, and P. C. Chamberlin (2010). Four Martian years of nightside upper thermosphere mass densities derived from electron reflectometry: Method extension and comparison with GCM simulations, J. Geophys. Res., 115, E07014, doi:10.1029/2009JE003529.

Mahaffy, P. R., M. Benna, T. King, D. N. Harpold, and R. et. al. Arvey (2015a). The Neutral Gas and Ion Mass Spectrometer on the Mars Atmosphere and Volatile Evolution Mission, Space Sci. Reviews, 195, 49-73, doi:10.1007/s11214-014-0091-1.

Mahaffy, P. R., M. Benna, M. Elrod, R. V. Yelle, S. W. Bougher, S. W. Stone, and B. M. Jakosky (2015b), Structure and composition of the neutral upper atmosphere of Mars from the MAVEN NGIMS investigation, Geophys. Res. Lett., 42, 8951-8957, doi: 10.1002/2015GL065329.

Medvedev, A., F. Gonzalez-Galindo, E. Yigit, A. G. Feofilov, F. Forget, and P. Hartogh (2015), Cooling of the Martian thermosphere by $\mathrm{CO} 2$ radiation and gravity waves: An intercomparison study with two general circulation models, J. Geophys. Res., 120, 913927, doi:10.1002/2015JE004802.

McDunn, T., S. W. Bougher, J. Murphy, M. D. Smith, F. Forget, J.-L.Bertaux, and F. Montmessin (2010), Simulating the Density and Thermal Structure of the Middle Atmosphere $(80-130 \mathrm{~km})$ of Mars Using the MGCM-MTGCM: A Comparison with MEX-SPICAM Observations, Icarus, 206, 5-17, doi:10.1016/j.icarus.2009.06.034.

Ridley, A., Y. Deng, and G. To'th (2006), The global ionosphere-thermosphere model, J. Atmos. Sol-Terr. Phys., 68, 839.

Seidelmann, P. K., et al. (2002), "Report of the IAU/IAG Working Group on Cartographic Coordinates and Rotational Elements of the Planets and Satellites: 2000", Celestial Mechanics and Dynamical Astronomy, 82, 83-110.

Seiff, A., and D. B. Kirk (1977), Structure of the atmosphere of Mars in summer at mid-latitudes. J. Geophys. Res., 82, 4364-78.

Tolson, R., G. Keating, R. Zurek, S. Bougher, C. Justus, S. Fritts (2006), Application of accelerometer data to atmospheric modeling during Mars aerobraking operations. J Spacft Rockets, 44, 1172-79, doi:10.2514/1.28472.

Tolson, R., E. Bemis, S. Hough, K. Zaleski, G. Keating, J. Shidner, S. Brown, A. Brickler, M. Scher, P. Thomas (2008), Atmospheric modeling using accelerometer data during Mars - Reconnaissance Orbiter aerobraking operations. J Spacft Rockets, doi:10.2514/1.34301.

Tolson, R. H., Lugo, R. A., Baird, D. T., Cianciolo, A. D., Bougher, S. W., and Zurek, R. M. (2017), "Atmospheric Modeling Using Accelerometer Data During Mars Atmosphere and Volatile Evolution (MAVEN) Flight Operations," 27 ${ }^{\text {th }}$ AAS/AIAA Space Flight Mechanics Meeting, San Antonio, TX, February 2017, AAS 17-273. 
Withers, P., M. Vogt, P. Mahaffy, M. Benna, M. Elrod, and B. M. Jakosky (2015), Changes in the thermosphere and ionosphere of Mars from Viking to MAVEN. Geophys. Res. Lett., 9071-79, doi:10.1002/2015GL065985.

Yigit, E., S. L. England, G. Liu, A. S. Medvedev, P. R. Mahaffy, T. Kuroda, and B. M. Jakosky, (2015), High-latitude gravity waves in the Martian thermosphere observed by MAVEN/NGIMS and modeled by a gravity wave scheme, Geophys. Res. Lett., 42, 8993-9000, doi:10.1002/2015GL065307.

Zurek, R., R. Tolson, D. Baird, M. Z. Johnson, S. W. Bougher (2015), Application of MAVEN Accelerometer and Attitude Control Data to Mars Atmospheric Characterization, Space Science Reviews, 195, 303-317, doi:10.1007/s11214-014-0095-x.

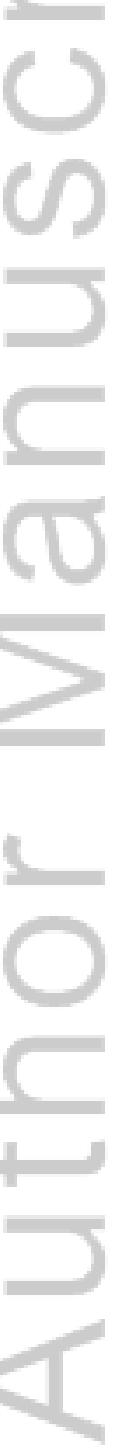

This article is protected by copyright. All rights reserved. 


\section{TABLES}

Table 1. Comparison of Nominal Science (NS) and Deep Dip (DD) MAVEN Orbits.

\begin{tabular}{|c|c|c|}
\hline Orbit Parameter & NS & DD \\
\hline Period & $4.5 \mathrm{~h}$ & $4.5 \mathrm{~h}$ \\
\hline Inclination & $75^{\circ}$ & $75^{\circ}$ \\
\hline Eccentricity & 0.47 & 0.47 \\
\hline Periapsis Altitude & $140-180 \mathrm{~km}$ & $115-135 \mathrm{~km}$ \\
\hline Targeted Periapsis Density & $0.05-0.15 \mathrm{~kg} / \mathrm{km}^{3}$ & $2.00-3.50 \mathrm{~kg} / \mathrm{km}^{3}$ \\
\hline Observed Periapsis Density & $\mathbf{0 . 0 2} * \mathbf{- 5 . 0 0} \mathbf{~ k g} / \mathbf{k m}^{\mathbf{3}}$ & $\mathbf{1 . 0 0 - 1 1 . 0 0 ~ k g} / \mathbf{k m}^{\mathbf{3}}$ \\
\hline
\end{tabular}

*Profiles where periapsis densities were $<0.1 \mathrm{~kg} / \mathrm{km}^{3}$ often exhibited noise features (e.g., Fig $4 d)$.

Table 2. Deep Dip (DD) Campaign Orbit Numbers and Times

\begin{tabular}{|c|c|c|c|c|c|c|}
\hline $\begin{array}{c}\text { Deep } \\
\text { Dip }\end{array}$ & $\begin{array}{c}\text { Start } \\
\text { Orbit }\end{array}$ & $\begin{array}{c}\text { End } \\
\text { Orbit }\end{array}$ & $\begin{array}{c}\text { Start } \\
\text { Date }\end{array}$ & $\begin{array}{c}\text { Start } \\
\text { Time }\end{array}$ & $\begin{array}{c}\text { End } \\
\text { Date }\end{array}$ & $\begin{array}{c}\text { End } \\
\text { Time }\end{array}$ \\
\hline 1 & 719 & 749 & $02 / 12 / 2015$ & $07: 12: 49$ & $02 / 17 / 2015$ & $23: 05: 45$ \\
\hline 2 & 1059 & 1086 & $04 / 17 / 2015$ & $05: 54: 49$ & $04 / 22 / 2015$ & $06: 33: 40$ \\
\hline 3 & 1506 & 1538 & $07 / 09 / 2015$ & $03: 02: 11$ & $07 / 14 / 2015$ & $23: 27: 01$ \\
\hline 4 & 1807 & 1838 & $09 / 03 / 2015$ & $03: 07: 46$ & $09 / 09 / 2015$ & $01: 04: 04$ \\
\hline 5 & 3290 & 3316 & $06 / 08 / 2016$ & $03: 17: 20$ & $06 / 12 / 2016$ & $22: 34: 16$ \\
\hline 6 & 3551 & 3589 & $07 / 26 / 2016$ & $04: 03: 20$ & $08 / 02 / 2016$ & $02: 01: 15$ \\
\hline
\end{tabular}

Table 3. Deep Dip Campaign Geometric Characteristics

\begin{tabular}{|c|c|c|c|c|c|}
\hline $\begin{array}{c}\text { Deep } \\
\text { Dip }\end{array}$ & Ls, deg & SZA, deg & LTST, hrs & Latitude & Characteristics \\
\hline 1 & 291 Early N. Winter & 108 & 18.3 & $45-40^{\circ} \mathrm{N}$ & $\begin{array}{c}\text { High N. Latitudes, past } \\
\text { evening terminator }\end{array}$ \\
\hline 2 & 328 Late S. Summer & 9 & 11.9 & $2-6^{\circ} \mathrm{S}$ & Near-noon at equator \\
\hline 3 & 11 Early S. Fall & 111 & 3.4 & $61-64^{\circ} \mathrm{S}$ & $\begin{array}{c}\text { High S. Latitudes, pre- } \\
\text { dawn }\end{array}$ \\
\hline 4 & 37 Mid-S. Fall & 91 & 16.0 & $66-62^{\circ} \mathrm{S}$ & $\begin{array}{c}\text { High S. Latitudes, } \\
\text { evening terminator }\end{array}$ \\
\hline 5 & $\begin{array}{c}\text { 166 Late N. } \\
\text { Summer }\end{array}$ & 96 & 5.3 & $36-32^{\circ} \mathrm{N}$ & $\begin{array}{c}\text { N. Mid-latitudes, dawn } \\
\text { terminator }\end{array}$ \\
\hline
\end{tabular}

This article is protected by copyright. All rights reserved. 
Confidential manuscript submitted to Journal of Geophysical Research

0.6

$1-5^{\circ} \mathrm{S}$

Midnight at equator (anti-solar point)

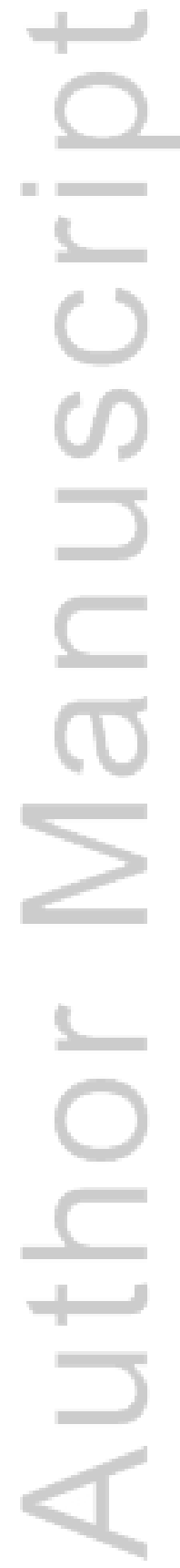

This article is protected by copyright. All rights reserved. 


\section{Confidential manuscript submitted to Journal of Geophysical Research}

\section{Figure Legends}

Figure 1. Traces of periapsis latitude, local solar time (LST), and areocentric longitude of the Sun, $\mathrm{L}_{\mathrm{s}}$, where spacecraft accelerometer data were obtained during the aerobraking missions of MGS, ODY, and MRO compared with the MAVEN periapsis trace. Numbers mark locations of six MAVEN Deep Dip campaigns conducted in the prime and first extended missions over one Mars year.

Figure 2. (Left) MAVEN spacecraft periapsis altitude for the primary science phase and most of the first extended mission, shown as a function of orbit number and areocentric longitude $\mathrm{L}_{\mathrm{s}}$. The jumps in altitudes reflect corridor maneuvers during the mission as densities at a given altitude changed with season and periapsis location. In addition to the nominal science (NS) orbits (blue), six Deep Dip (DD, red) campaigns were conducted at lower altitudes, with intermediate steps in altitude into and out of the DD corridor. (Right) The subsolar latitude (green) and the spacecraft periapsis latitude (blue) are shown as a function of orbit number and calendar date (month/year). Vertical red bars indicate the time of the DD campaigns.

Figure 3. Parametric trace of MAVEN periapsis during the prime and first extended missions: (Left) True local solar time (TLST, blue) and solar zenith angle (SZA, green) as a function of orbit number and $\mathrm{L}_{\mathrm{s}}$. (Right) $\mathrm{L}_{\mathrm{s}}$ (blue) and Mars-Sun distance (green) for each MAVEN periapsis. Shown as a function of MAVEN orbit number and calendar date (month/year). Vertical bars (red) indicate DD campaigns.

Figure 4. Six panel pairs (two per row) show representative samples of the accelerometer profiles for the identified orbits. The $1 \mathrm{~Hz}$ accelerometer data have been smoothed with a 99point running mean (blue curves). (Left Panels) The accelerometer-derived densities are shown in blue and the ACC profile fits (see Section 4) are in red. The altitude profile is dashed black. The horizontal axes are (secs) from periapsis $(t=0)$. (Right Panels) The smoothed accelerometer-derived density variation with altitude is in blue. The altitude ranges used to derive scale heights within $10 \mathrm{~km}$ of periapsis and on the ingress and egress legs at a reference altitude of $150 \mathrm{~km}$ are black line segments (e.g., arrows). Numerical values of the resulting density scale heights are given (in and above the right-hand panels of each pair).

Figure 5. Four parameters resulting from the ACC-fits for MAVEN aeropasses (see text). Model coefficients interpreted in terms of density $\rho$ (upper left), density scale height $\mathrm{H}_{\mathrm{s}}$ (lower left), and their along track gradients $\nabla_{\mathrm{t}}$ (right). Deep Dip (red) and Nominal Science (blue) periapsis values are shown. Shaded boxes (upper left) indicate the target corridors for periapsis density for DD and NS orbits.

Figure 6. Orbit-to-orbit variation represented by the standard deviation $\sigma$ of ACC-fit periapsis parameters: $\ln \rho$ (upper left) and along-track gradients of density and $\mathrm{H}_{\mathrm{s}}$ (right column) for each of 77 bins chosen to minimize variation with altitude, latitude and solar zenith angle (see 
Confidential manuscript submitted to Journal of Geophysical Research

text). Also shown are the bin-averaged $\mathrm{H}_{\mathrm{s}}$ values (lower left). (Magenta/black bar indicates periods when periapsis was in day/night.)

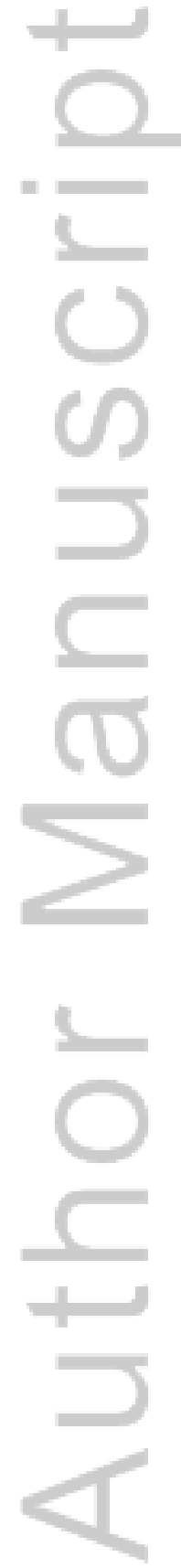

This article is protected by copyright. All rights reserved. 


\section{Confidential manuscript submitted to Journal of Geophysical Research}

Figure 7. (Top) Derived ACC-fit periapsis densities extrapolated to a constant reference altitude of $150 \mathrm{~km}$ and averaged over 11 contiguous orbit sets. Red curve is a parametric fit (Eq. 6) to dependences on seasonal and diurnal (time-of-day) insolation. (Second panel) This orbit-toorbit uncertainty is derived as a deviation from the mean for each of the 11 contiguous orbit sets (see text). (Third panel) The orbit-to-orbit variability is normalized by the mean density for the 11 contiguous orbits and a model fit derived (red curve and Eq. 7). (Bottom) The variations of solar zenith angle (blue curve) and Sun-Mars distance (green) used in the fits. Magenta symbols (+) mark DD orbits. The horizontal axes indicate calendar month/year (top), areocentric longitude $\mathrm{L}_{\mathrm{S}}$ (middle) and MAVEN orbit number (periapsis, bottom).

Figure 8. Atmospheric scale heights derived from binned ACC-fits near MAVEN periapsis altitudes as a function of altitude $\mathrm{h}$ (left panel) and solar zenith angle (SZA, middle). Red symbols are averages derived for the Deep Dip bins, with open circles calling out DD5 and DD6. Blue symbols were derived for nominal science orbits and averaged over the bins discussed earlier (e.g., Fig. 6 and related discussion). Third panel (far right) shows the residuals between the binned nominal science orbit data and the simple linear model fit in $\cos ($ SZA) and delta altitude ( $\delta \mathrm{h})$ above $150 \mathrm{~km}(\mathrm{Eq} .8)$.

Figure 9. Periapsis ACC-fit densities versus altitude for the 6 Deep Dip campaigns of the MAVEN primary and first extended missions. The target density corridor for Deep Dip maneuvers is shaded.

Figure 10. (Top) Comparison of total delta-V derived from accelerometer data and from the navigation OPTG files for the six DD campaigns. (Bottom) Per cent (\%) differences between these quantities. The orbit number here is arbitrary but sequential within each DD campaign.

Figure 11. Comparisons of accelerometer densities with Mars Global Ionosphere Thermosphere Model (M-GITM) simulations for each DD campaign. (Red) Data for each orbit are smoothed with 99-point running mean; for all orbits in the DD campaign, heavy curve shows the average and lines show 1-sigma variation. (Blue) Simulated densities from M-GITM for all model longitudes at the indicated true local time (LT); heavy curve is their average. Ingress (approaching periapsis) portions of the orbits are shown here.

Figure 12. Comparisons of accelerometer densities with Mars Global Ionosphere Thermosphere Model (M-GITM) simulations for each DD campaign. (Dark Blue) Data for each orbit are smöothed with 99-point running mean; for all orbits in the DD campaign, heavy curve shows the average and lines show 1-sigma variation. (Black) Simulated densities from M-GITM for all model longitudes at the indicated true local time (LT); heavy curve is their average. Egress (departing periapsis) portions of the orbits are shown here. 
Figure 1

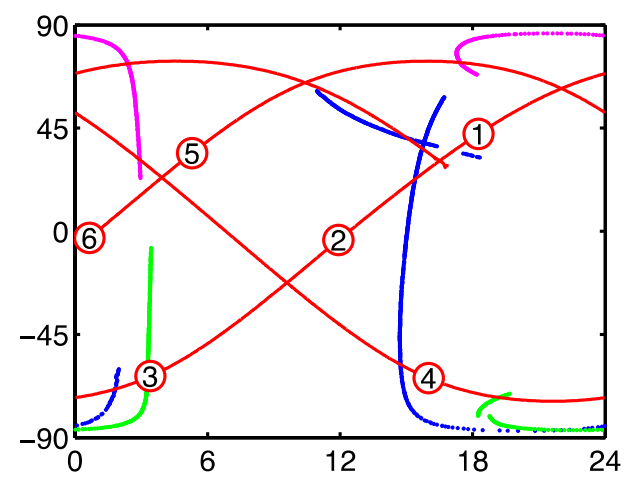

This article is protected by copyright. All rights reserved. 
Figure 2
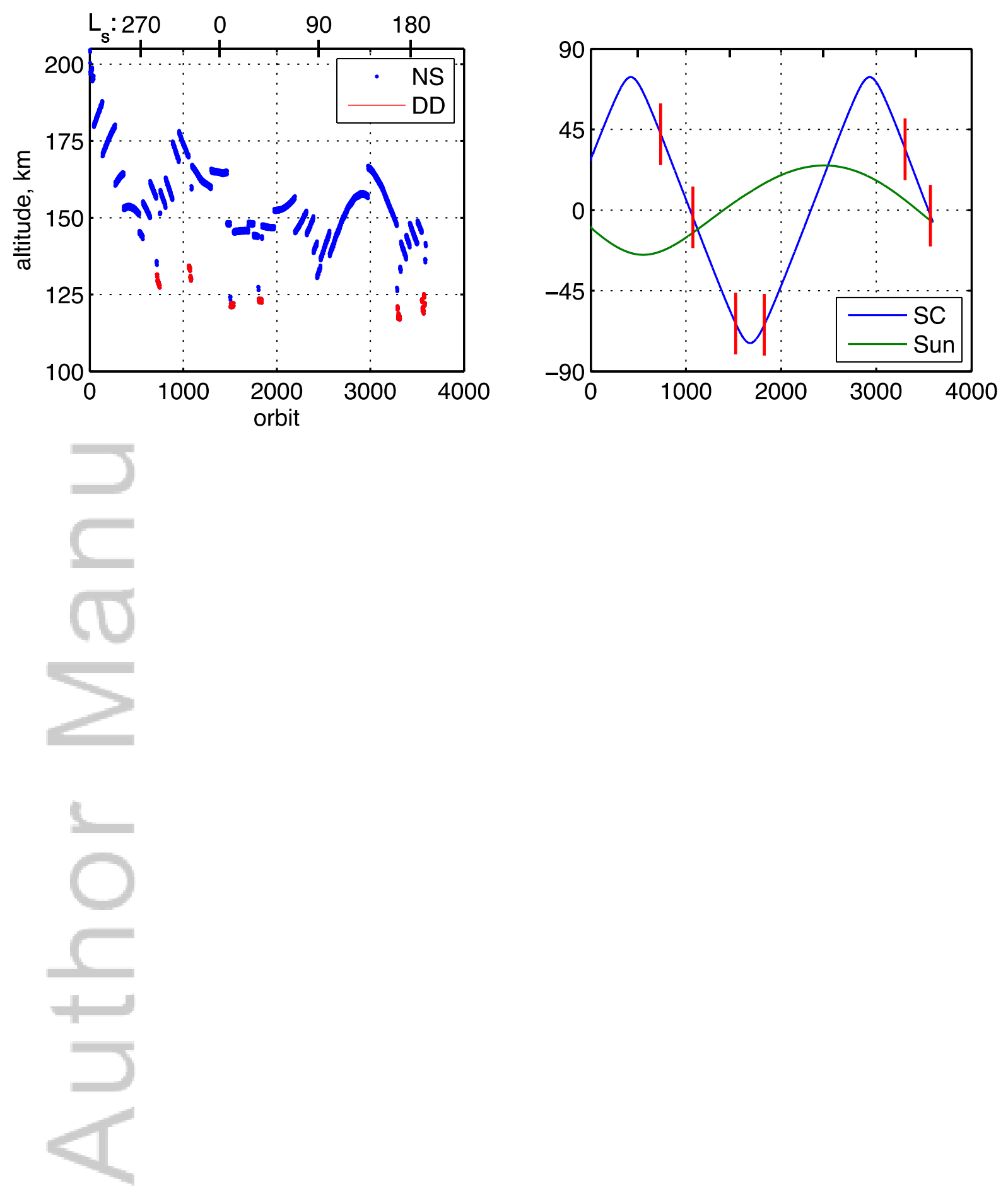

This article is protected by copyright. All rights reserved. 
Figure 3
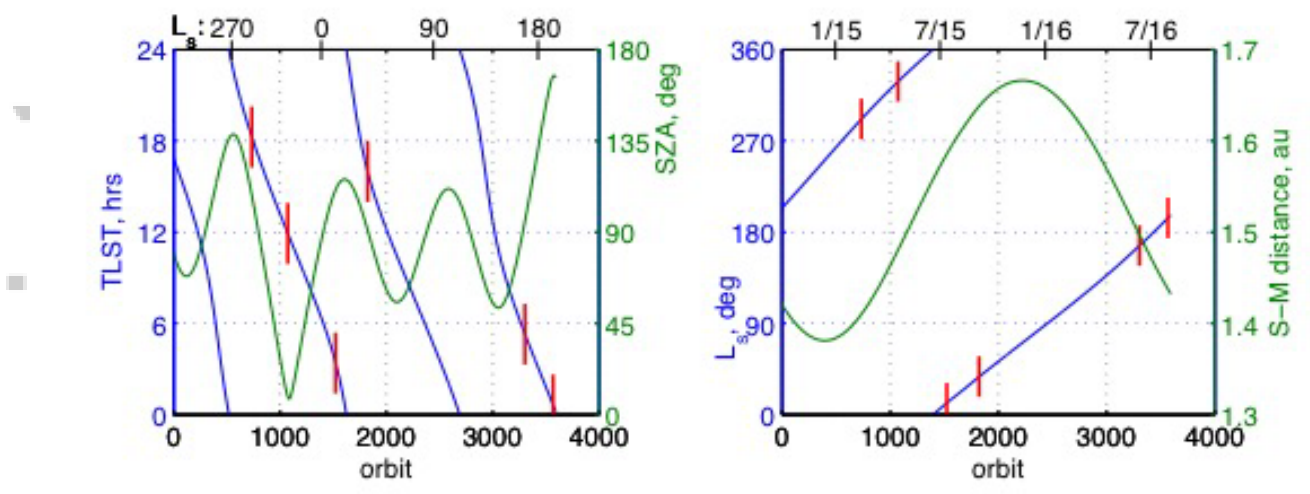
Figure 4
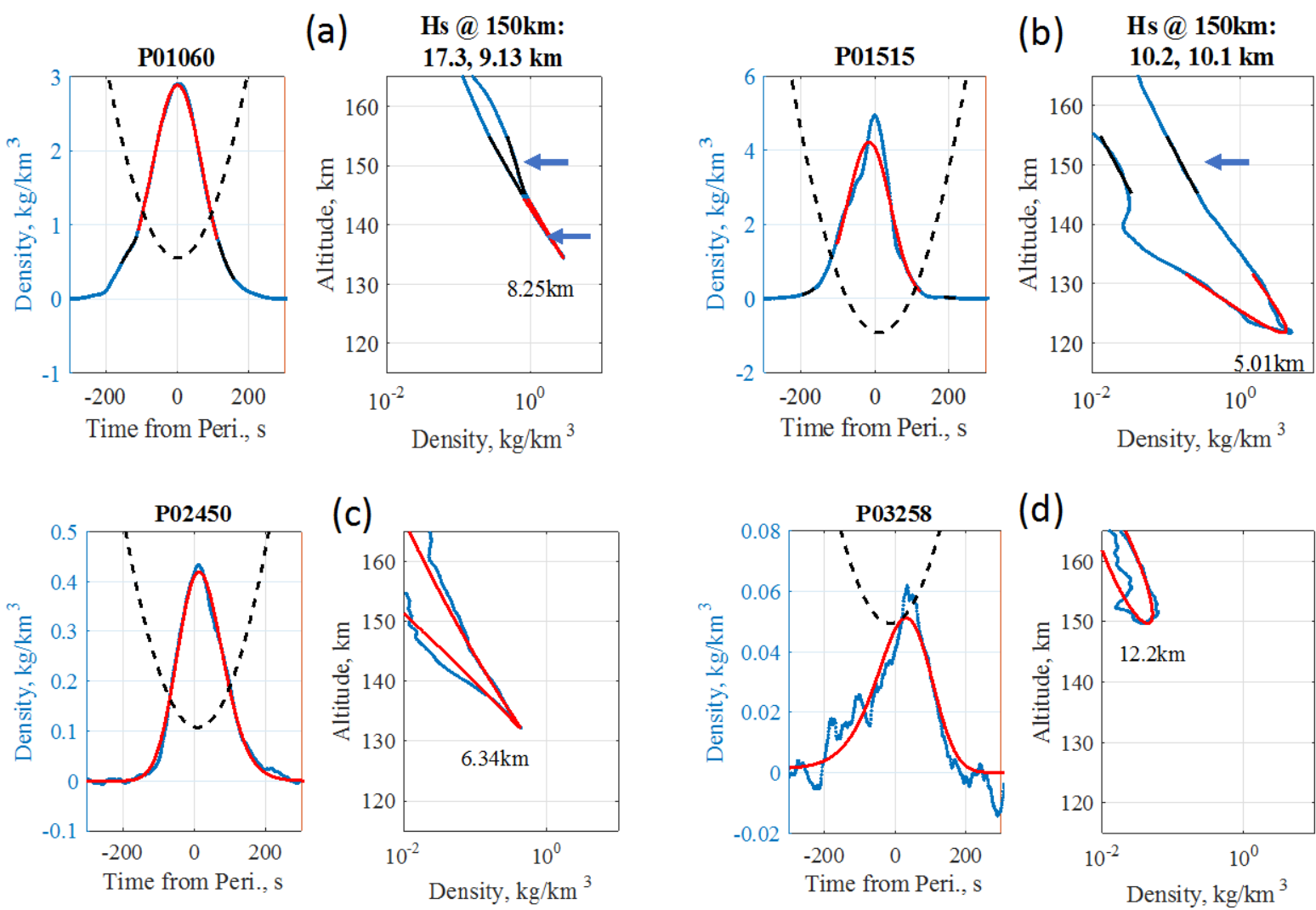

(d)
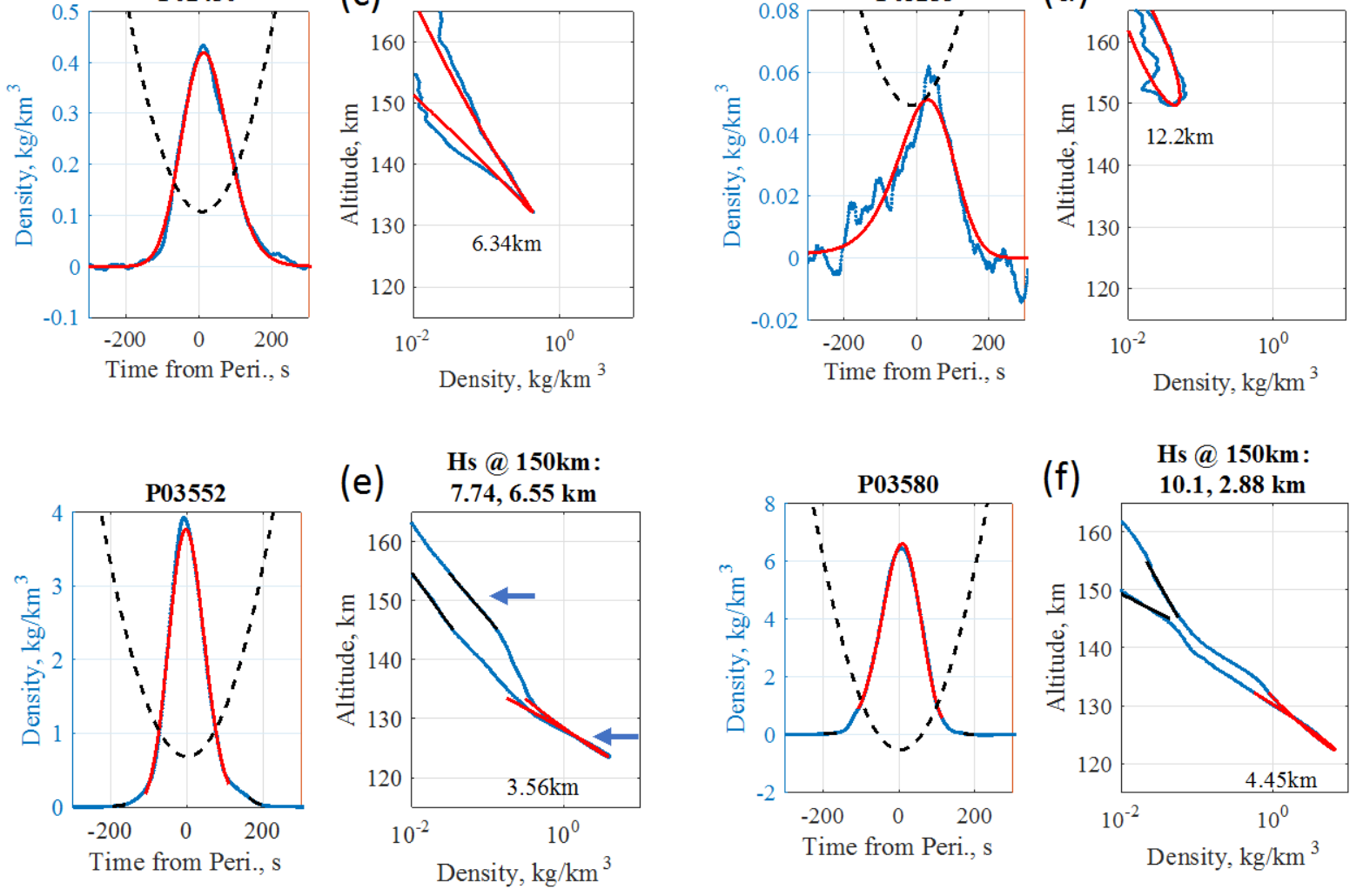
Figure 5
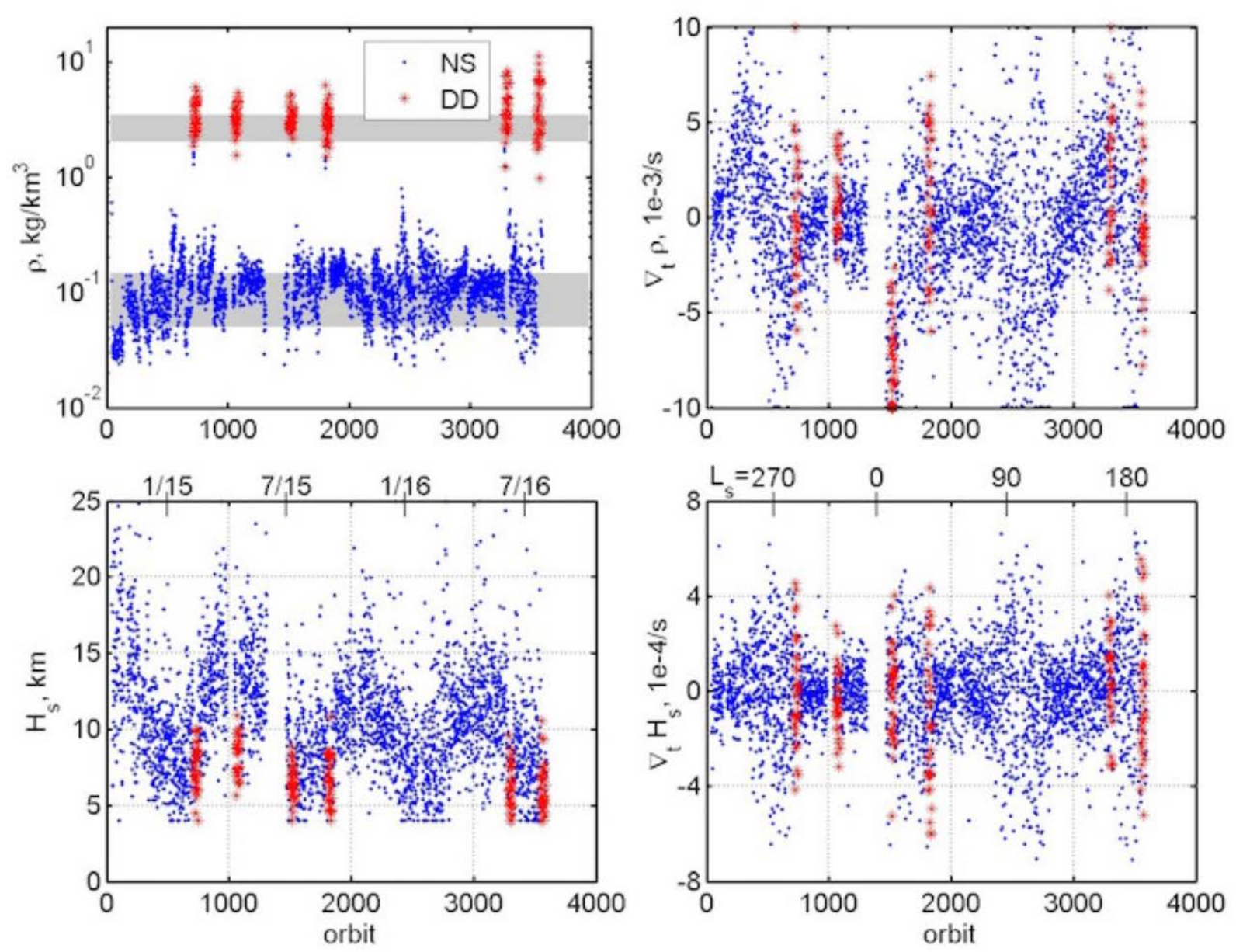

This article is protected by copyright. All rights reserved. 
Figure 6
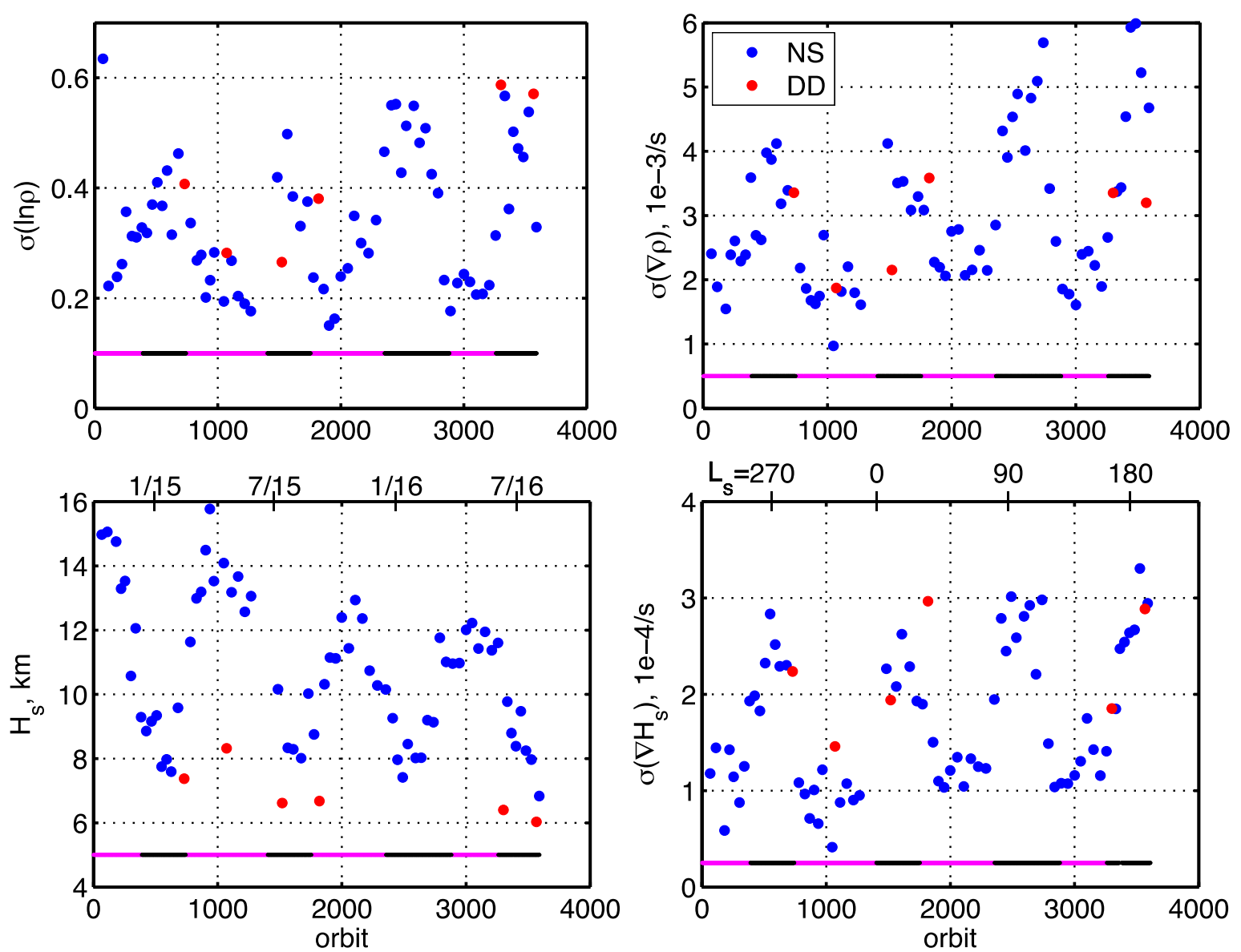

This article is protected by copyright. All rights reserved. 
Figure 7
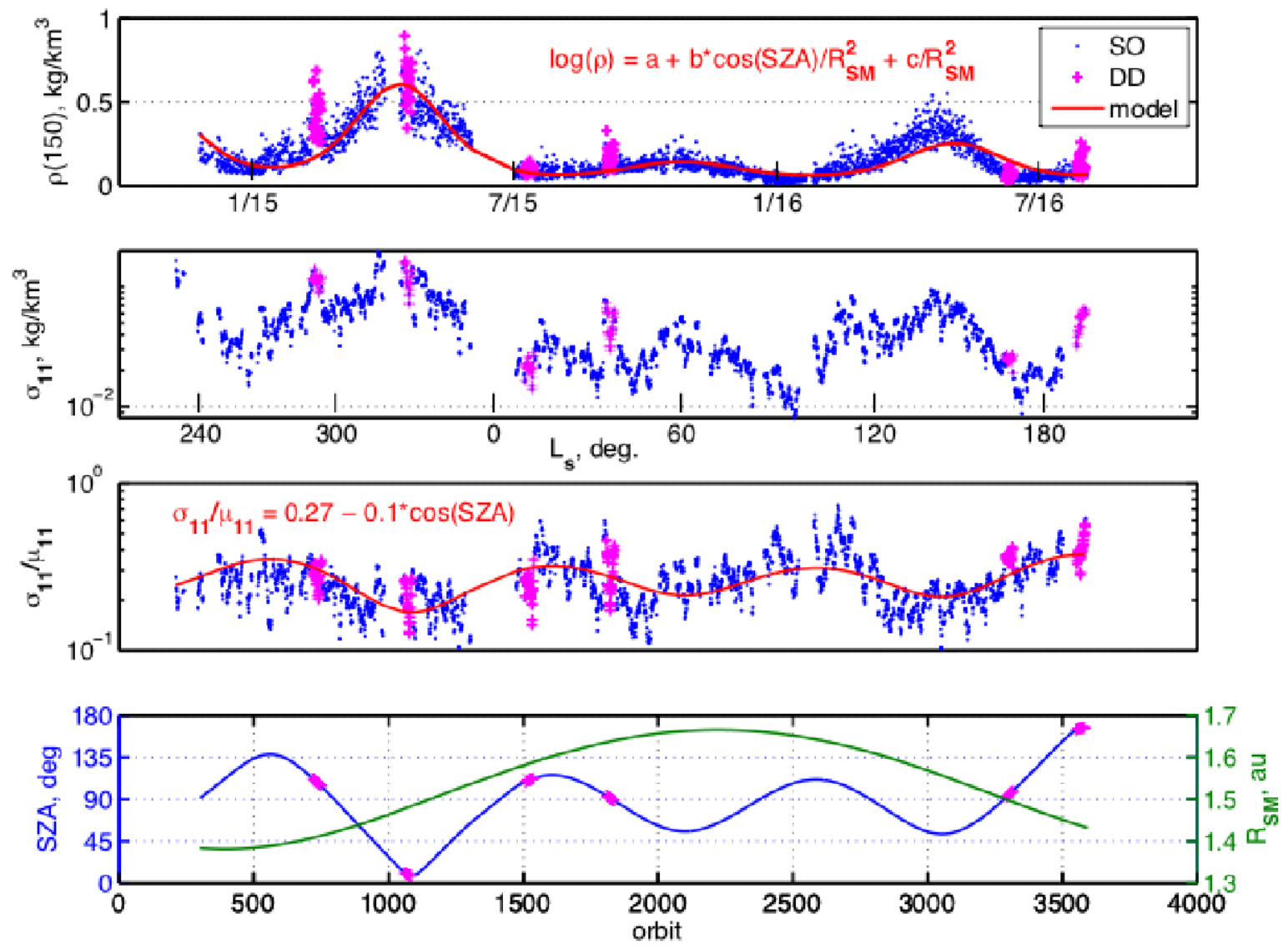

This article is protected by copyright. All rights reserved. 
Figure 8
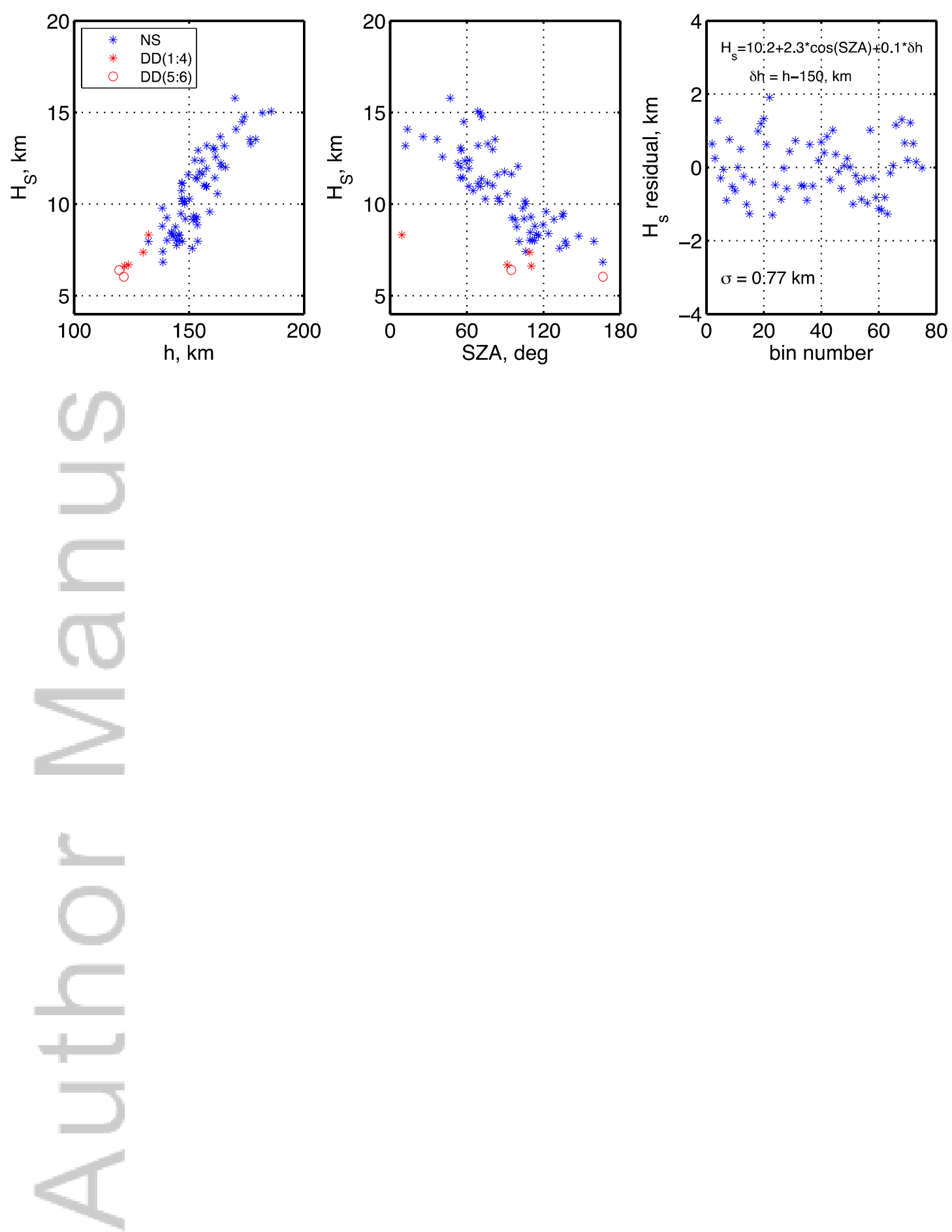

This article is protected by copyright. All rights reserved. 
Figure 9

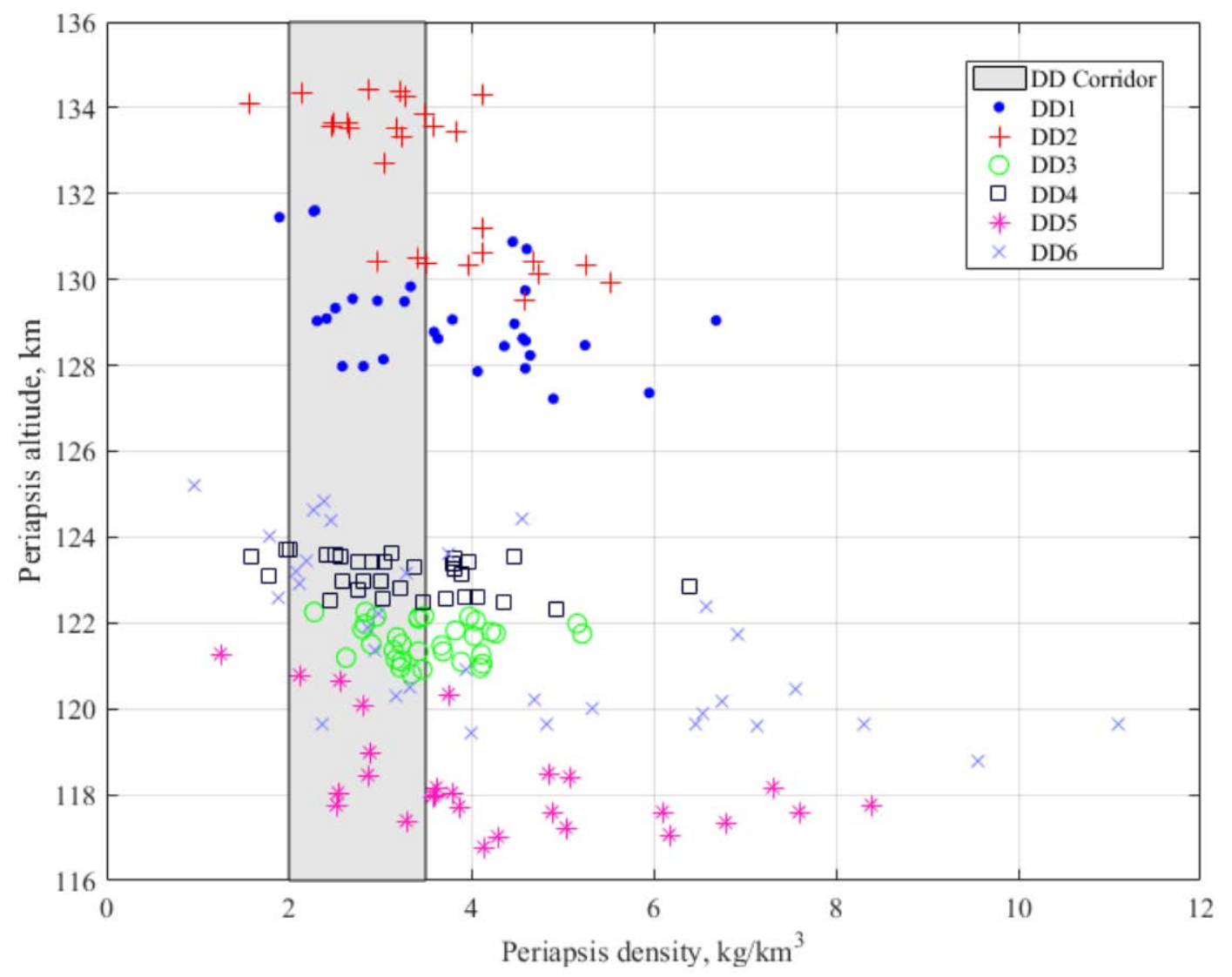

This article is protected by copyright. All rights reserved. 
Figure 10
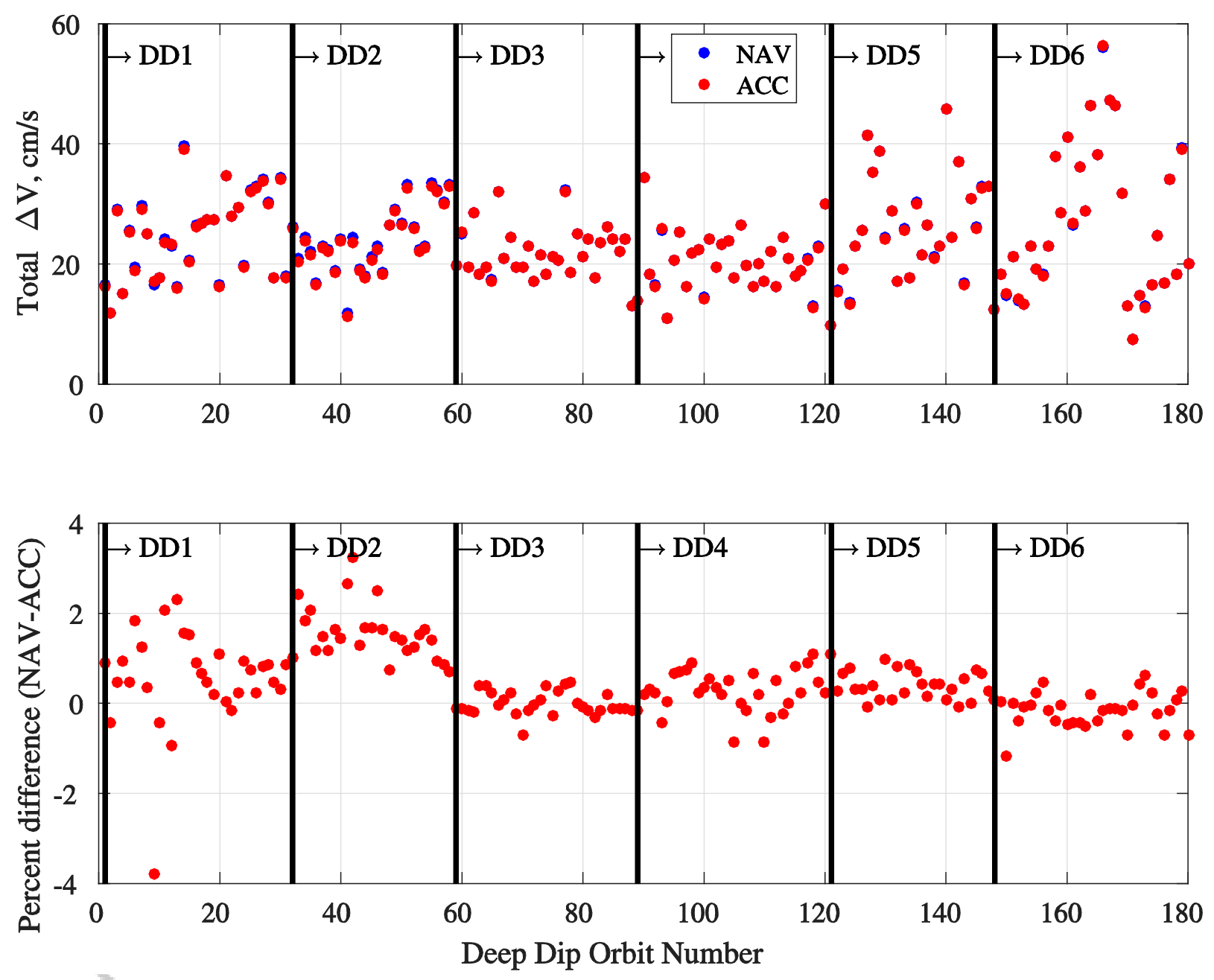

This article is protected by copyright. All rights reserved. 
Figure 11

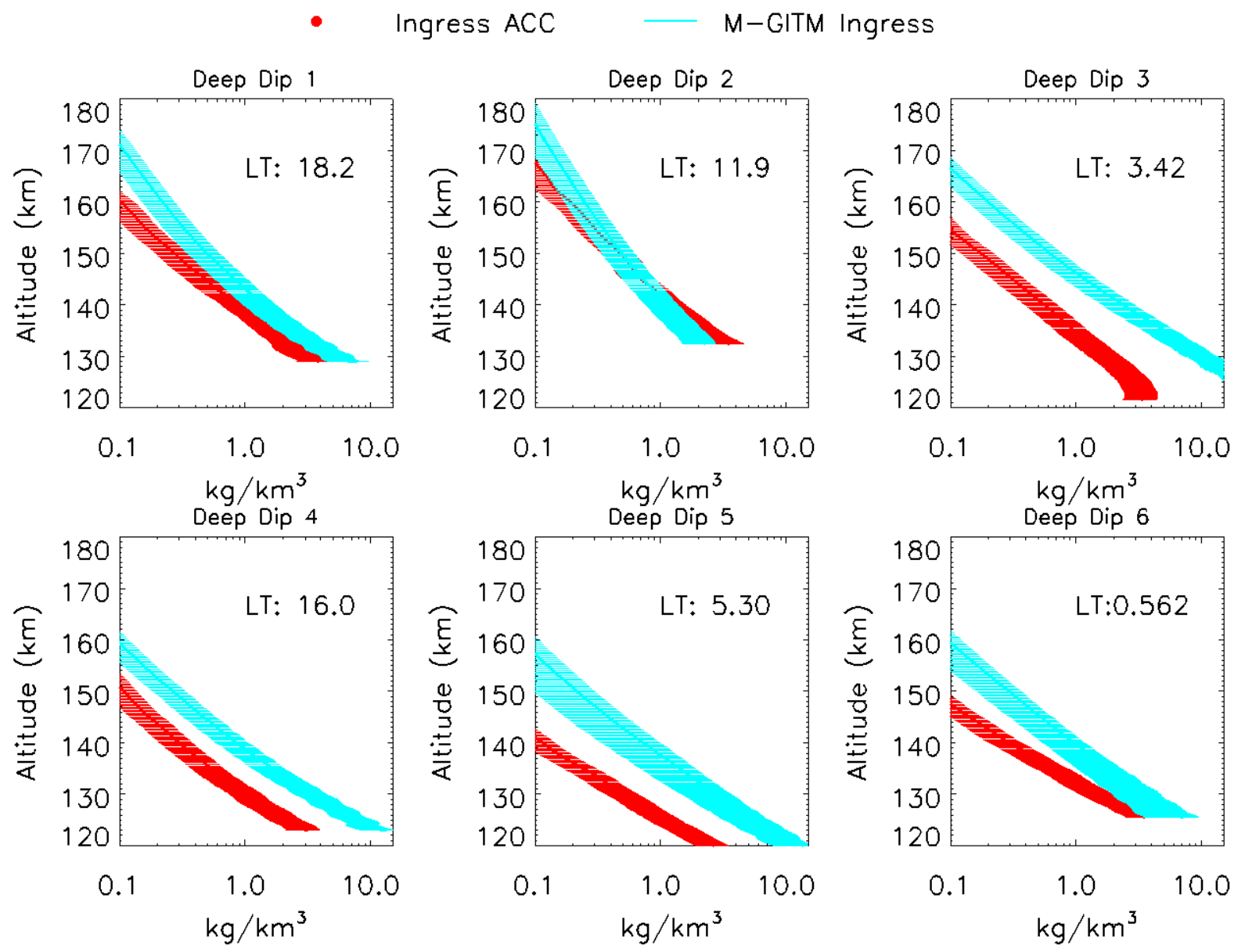

This article is protected by copyright. All rights reserved. 
Figure 12

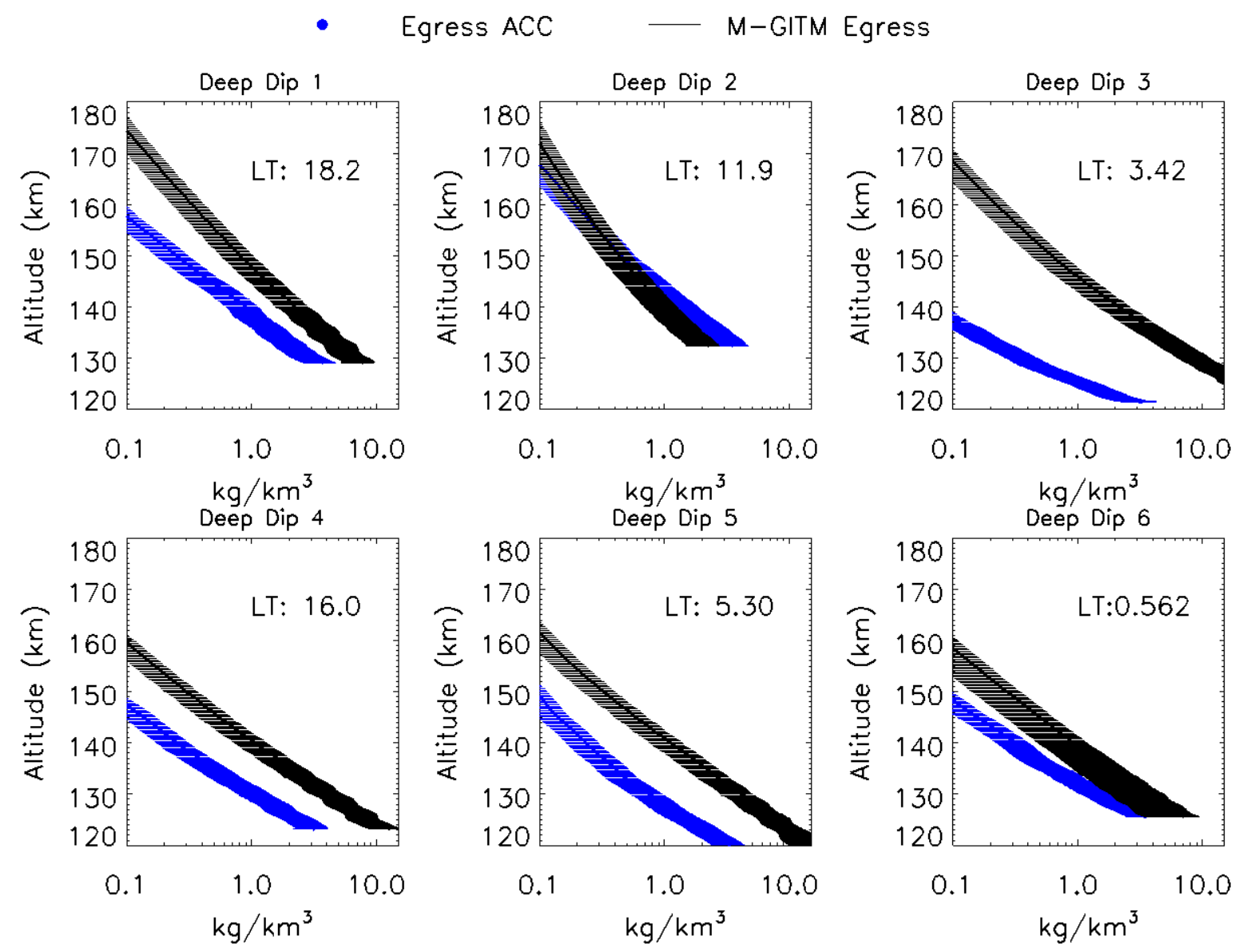

This article is protected by copyright. All rights reserved. 

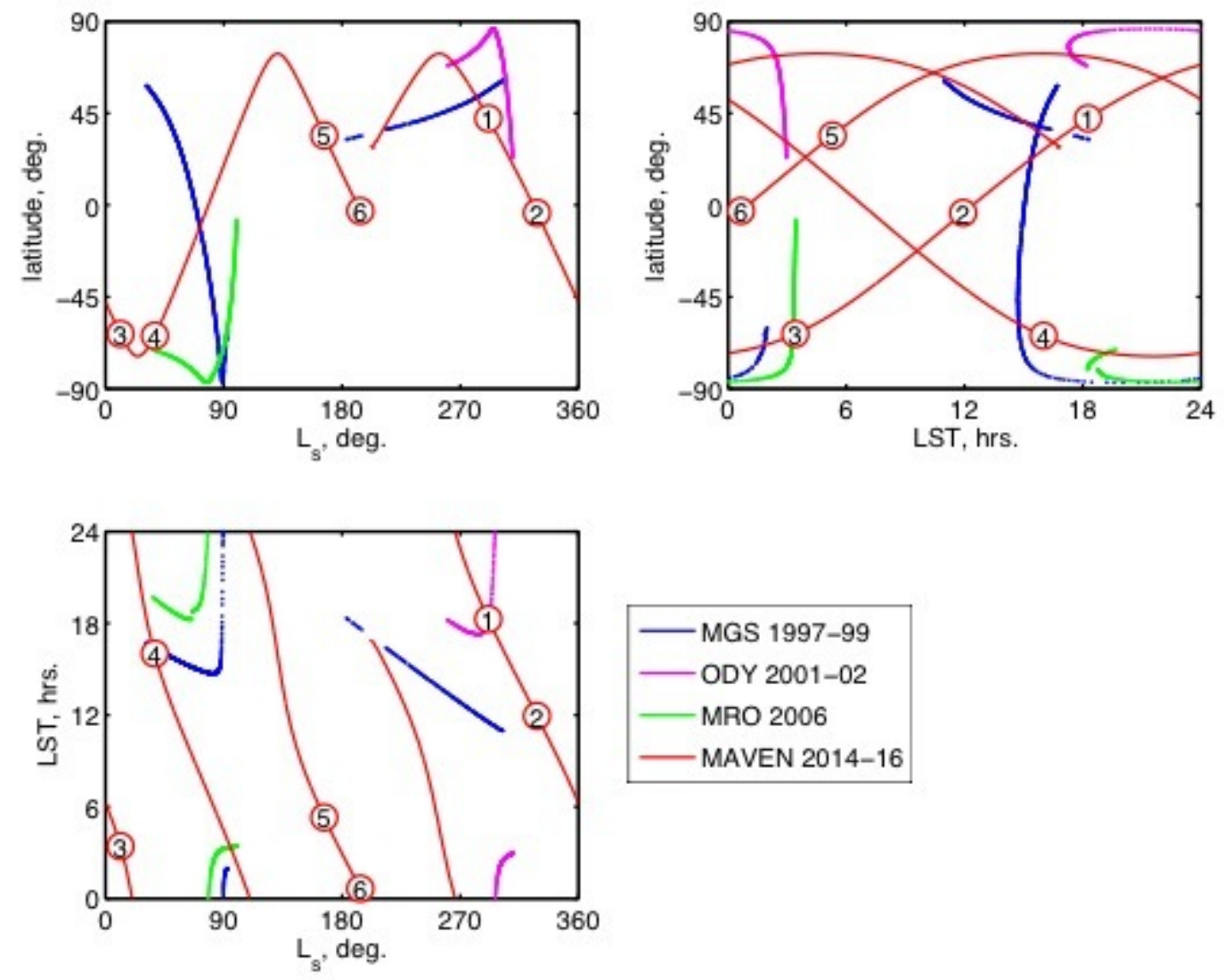

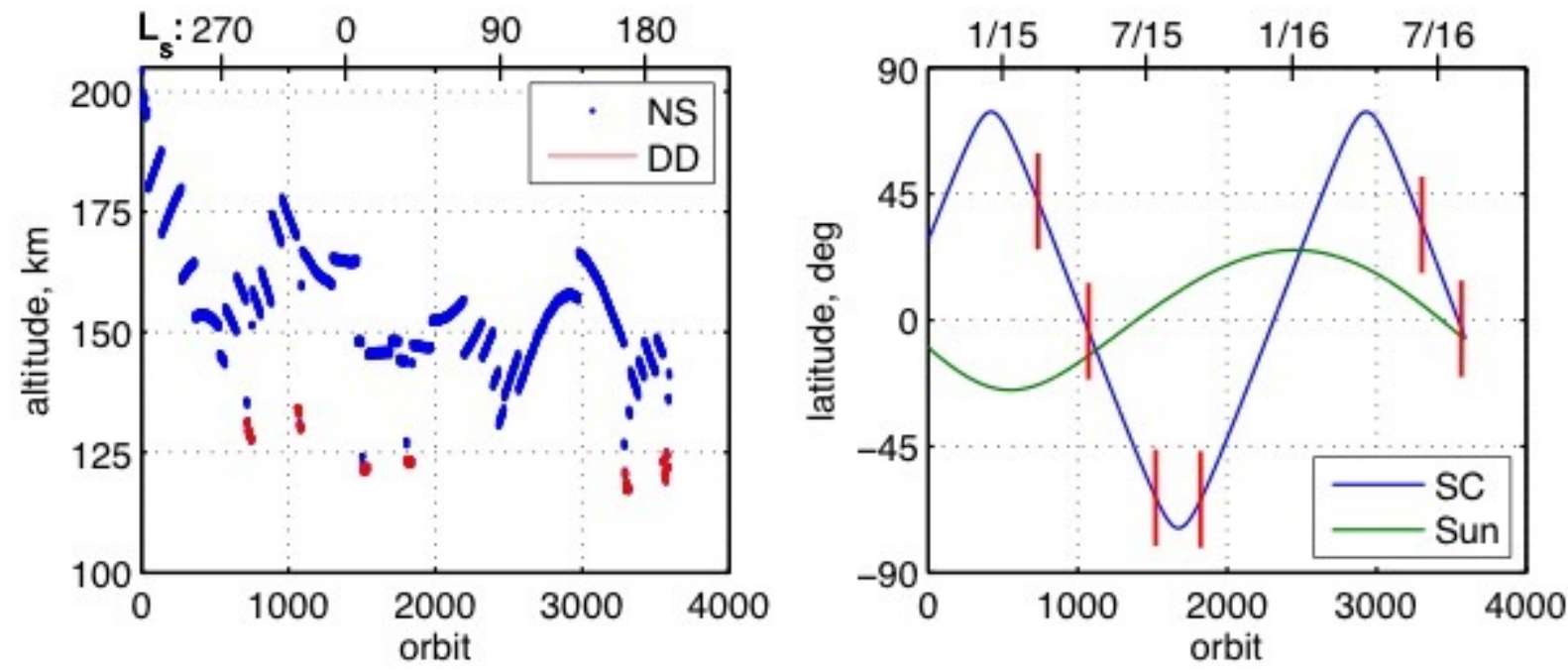

2016JA023641-f02-z-.jpg

This article is protected by copyright. All rights reserved. 

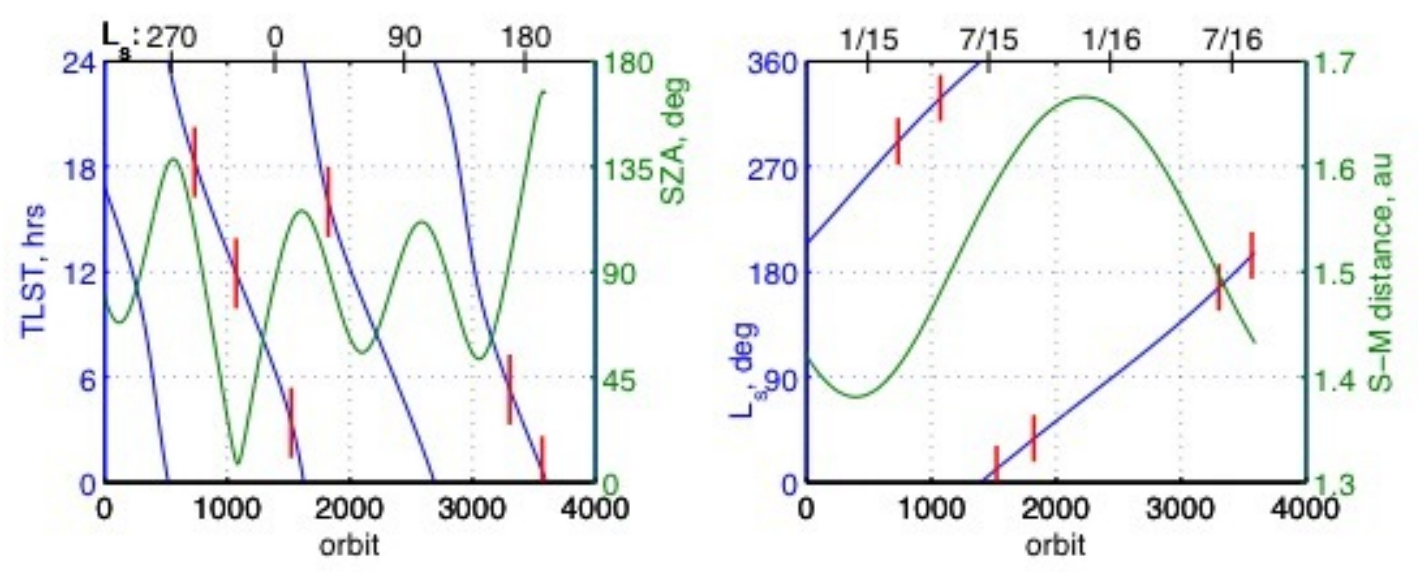

2016JA023641-f03-z-.jpg

This article is protected by copyright. All rights reserved. 

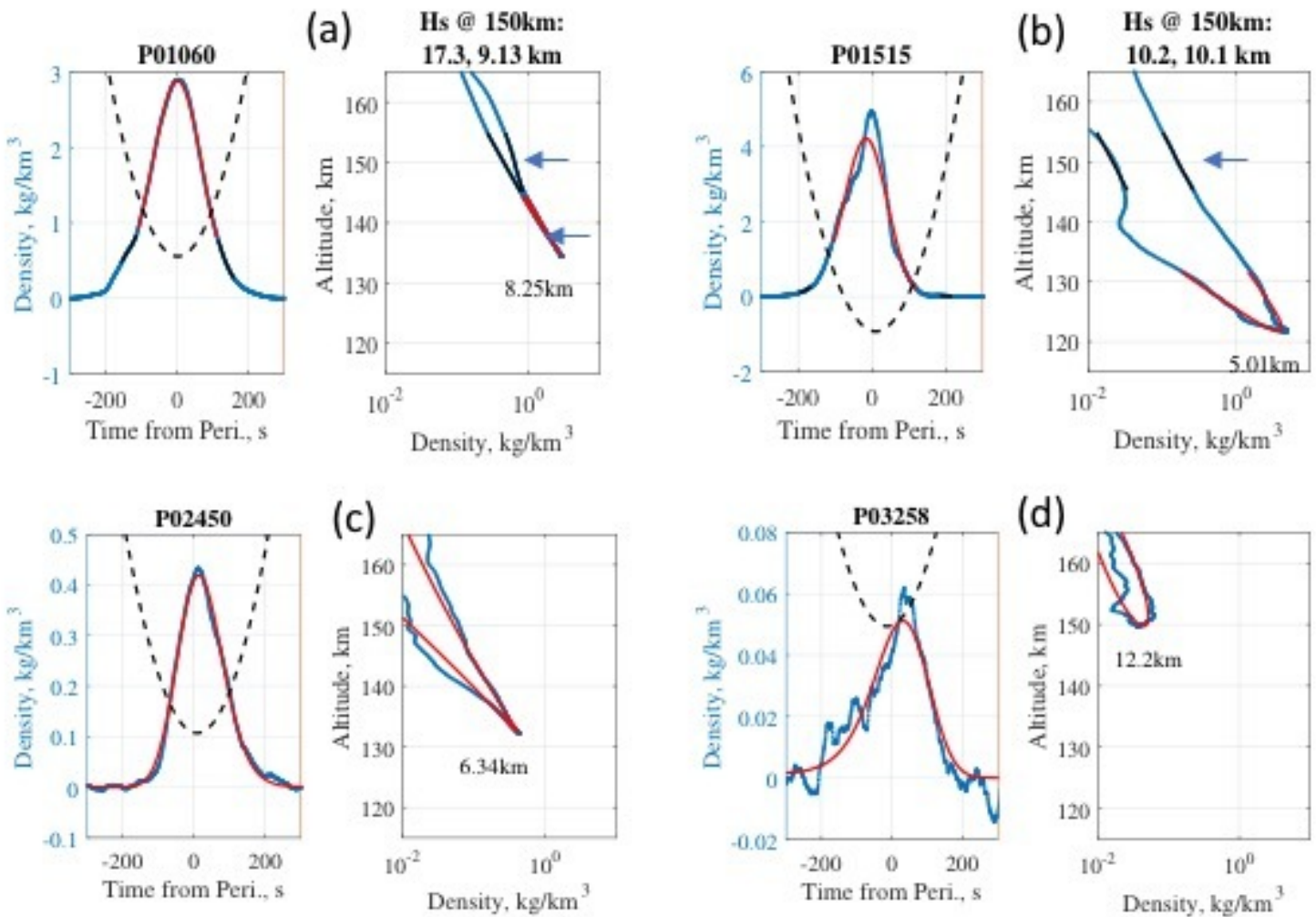

(d)
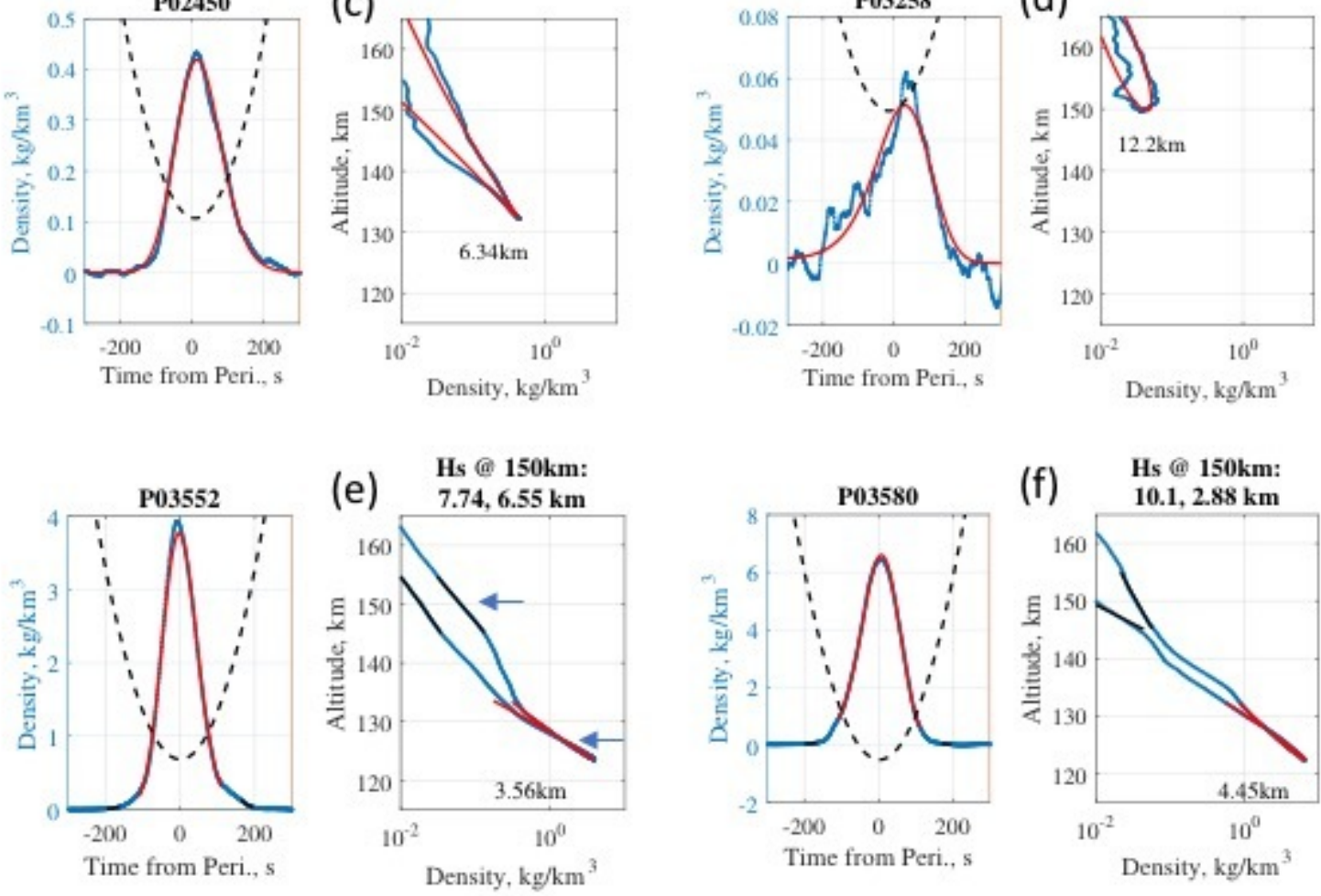

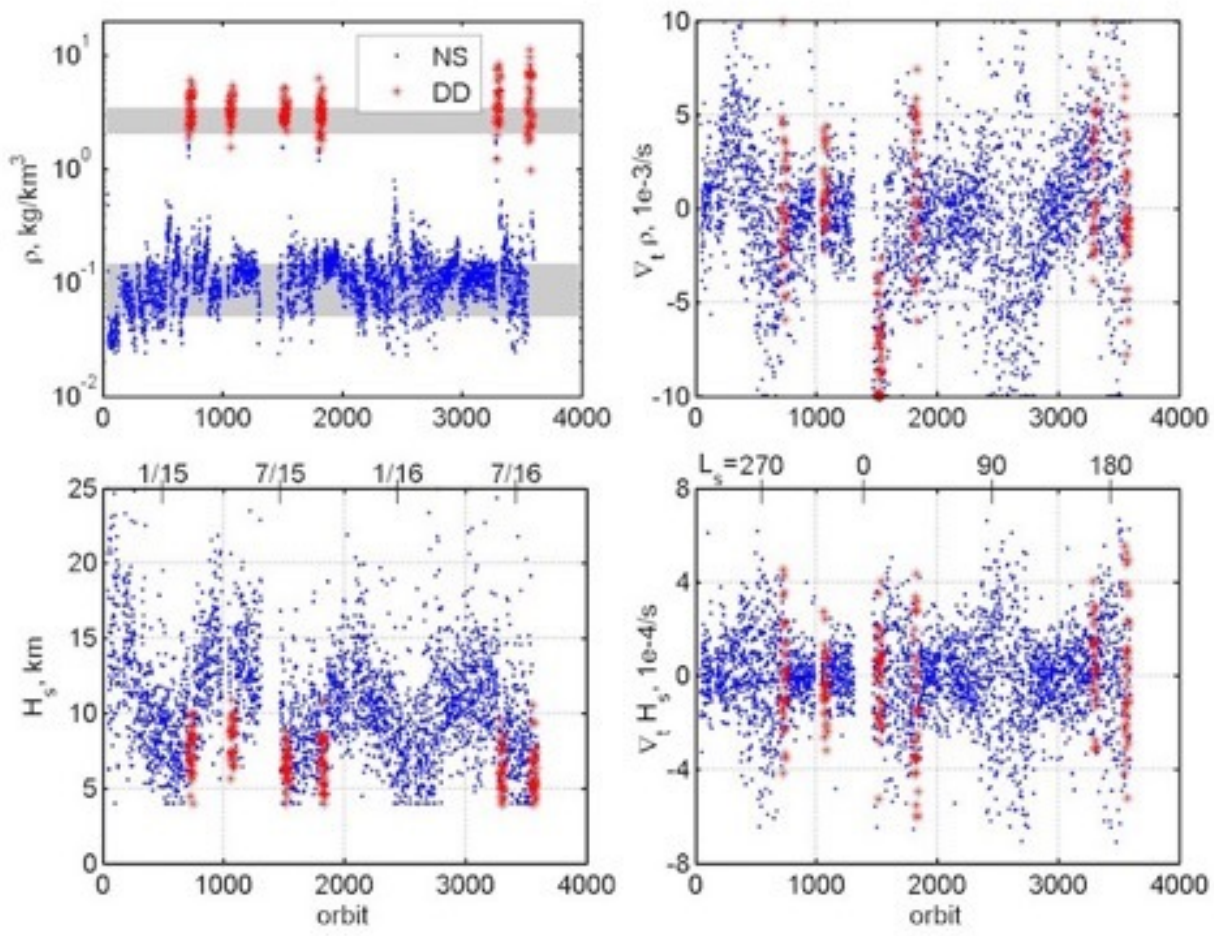

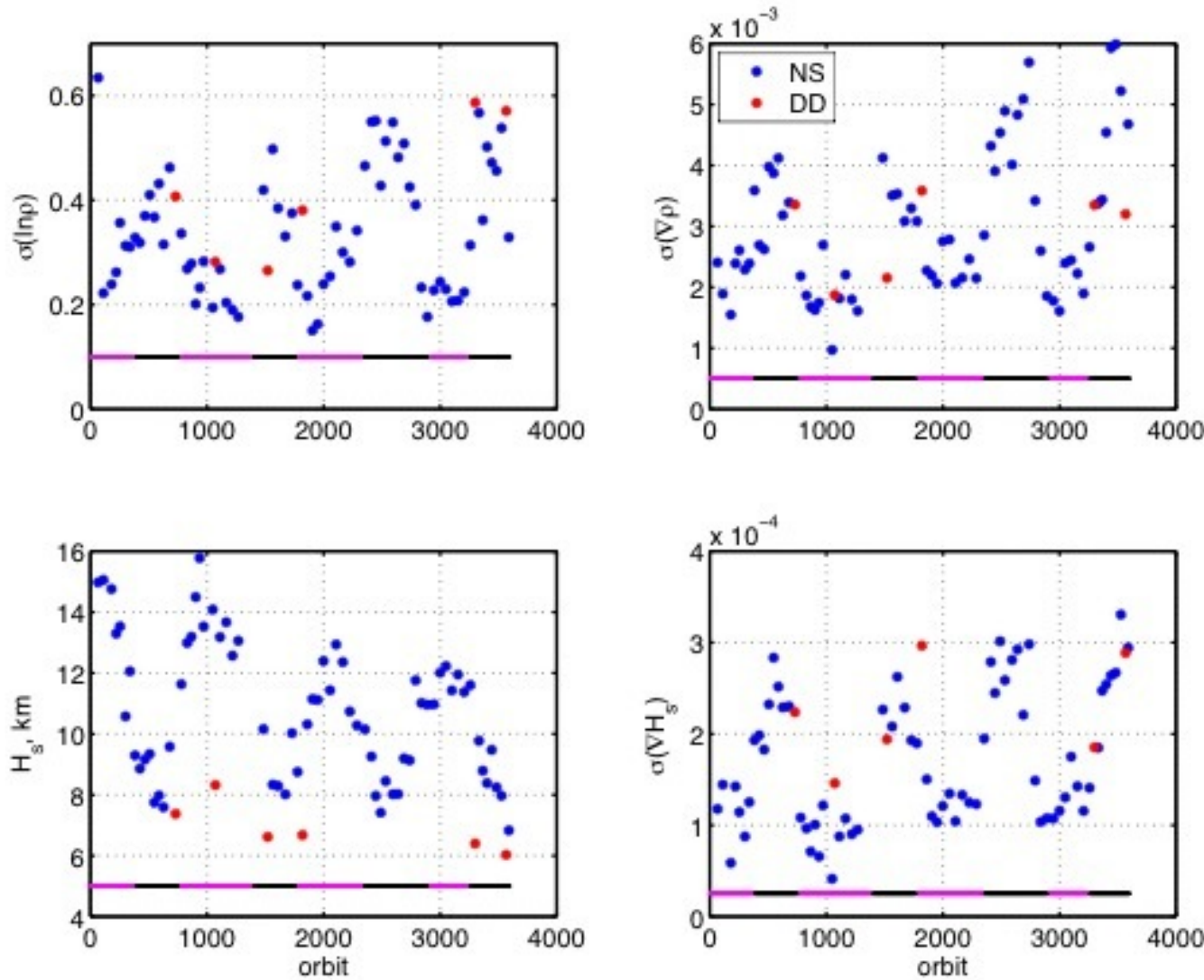

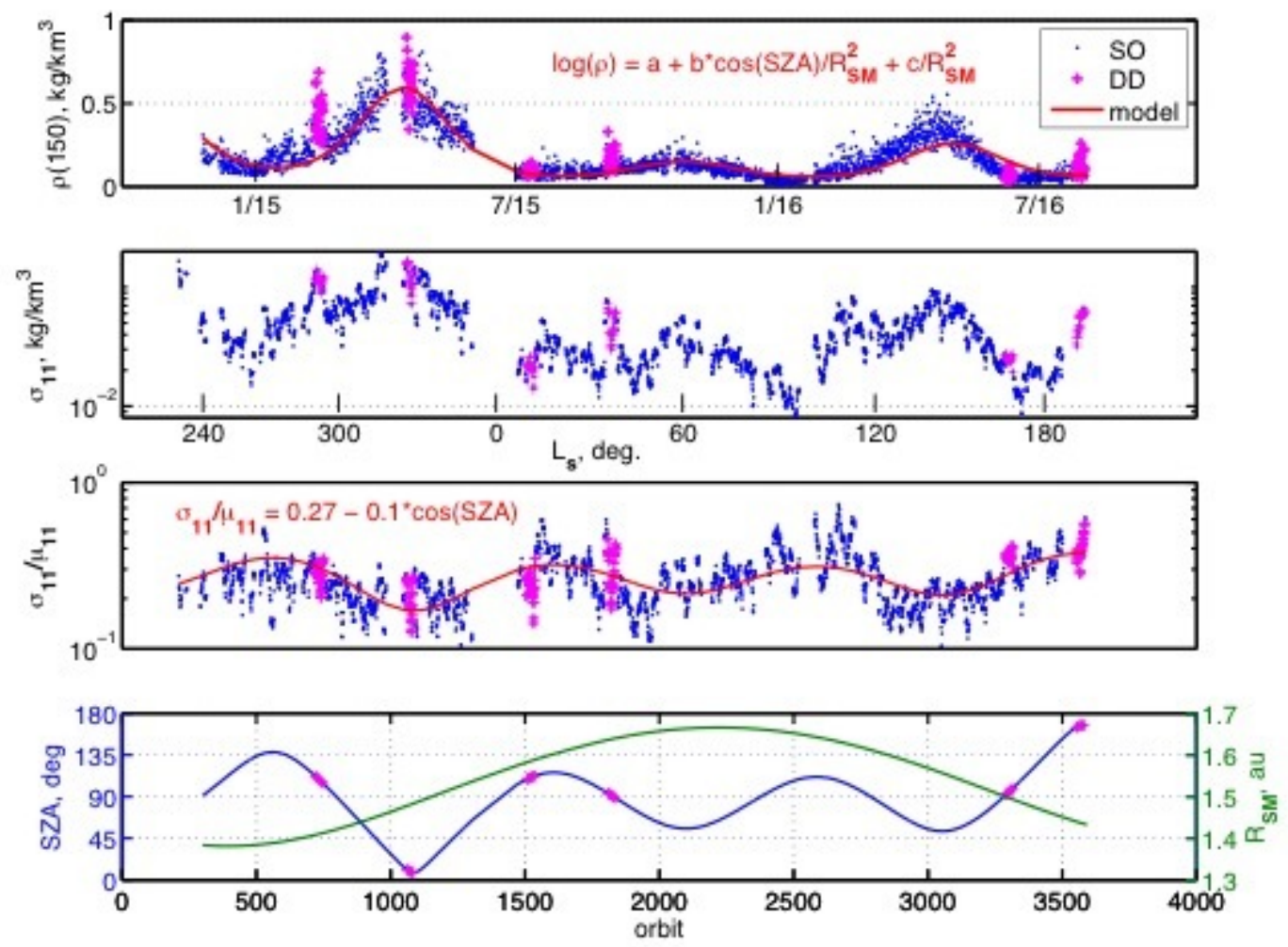

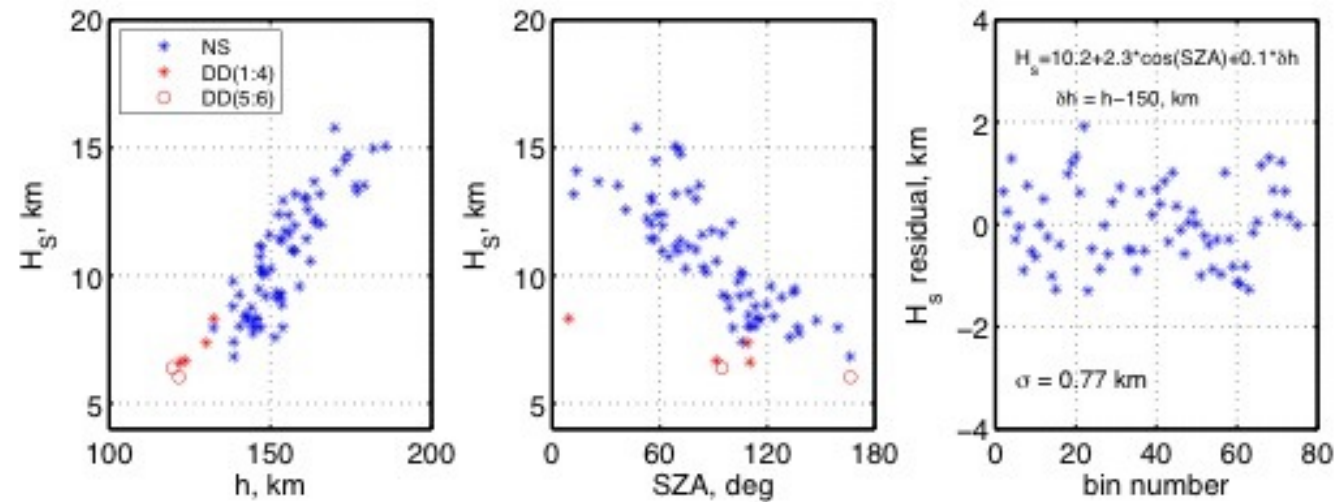


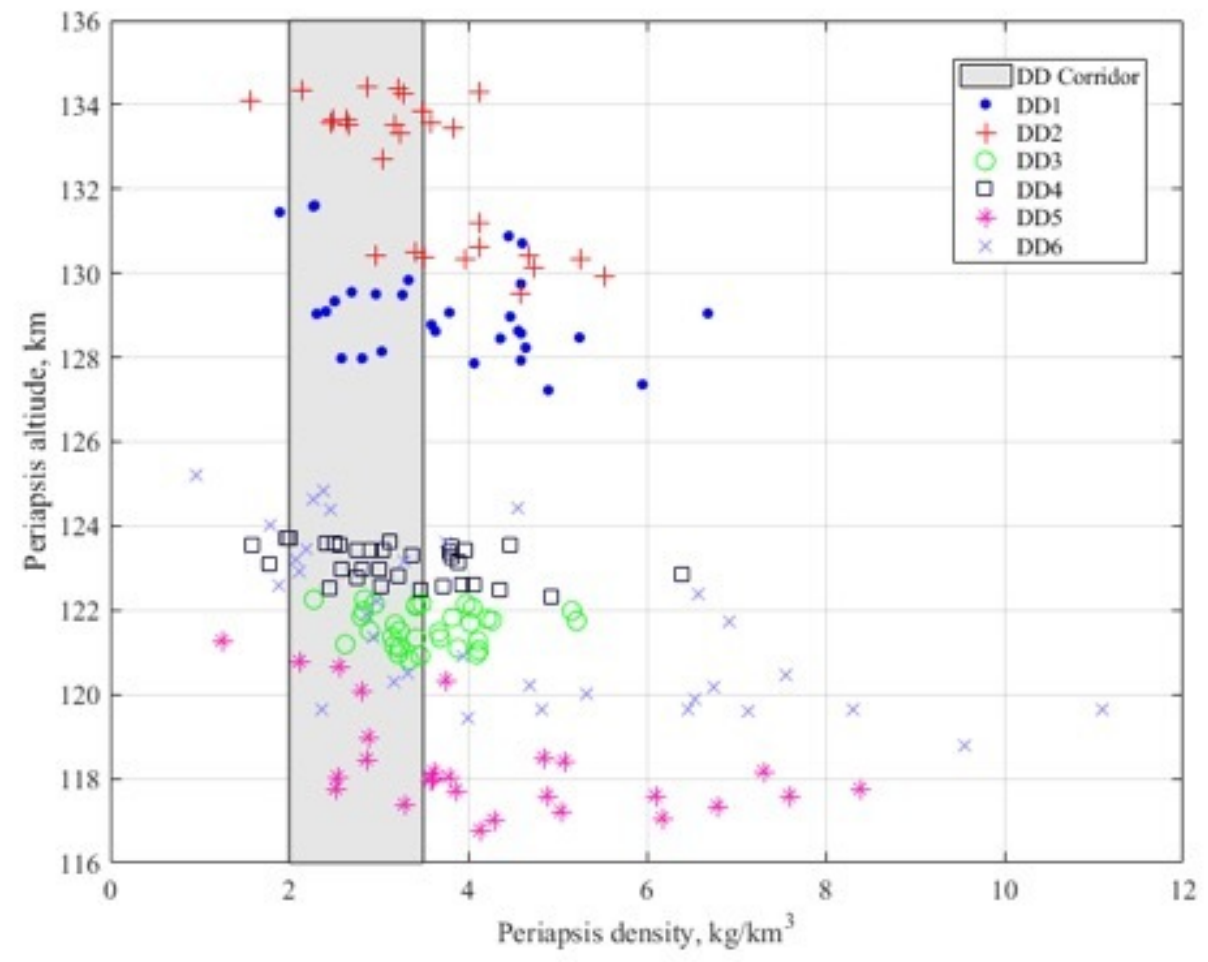

2016JA023641-f09-z-.jpg

This article is protected by copyright. All rights reserved. 

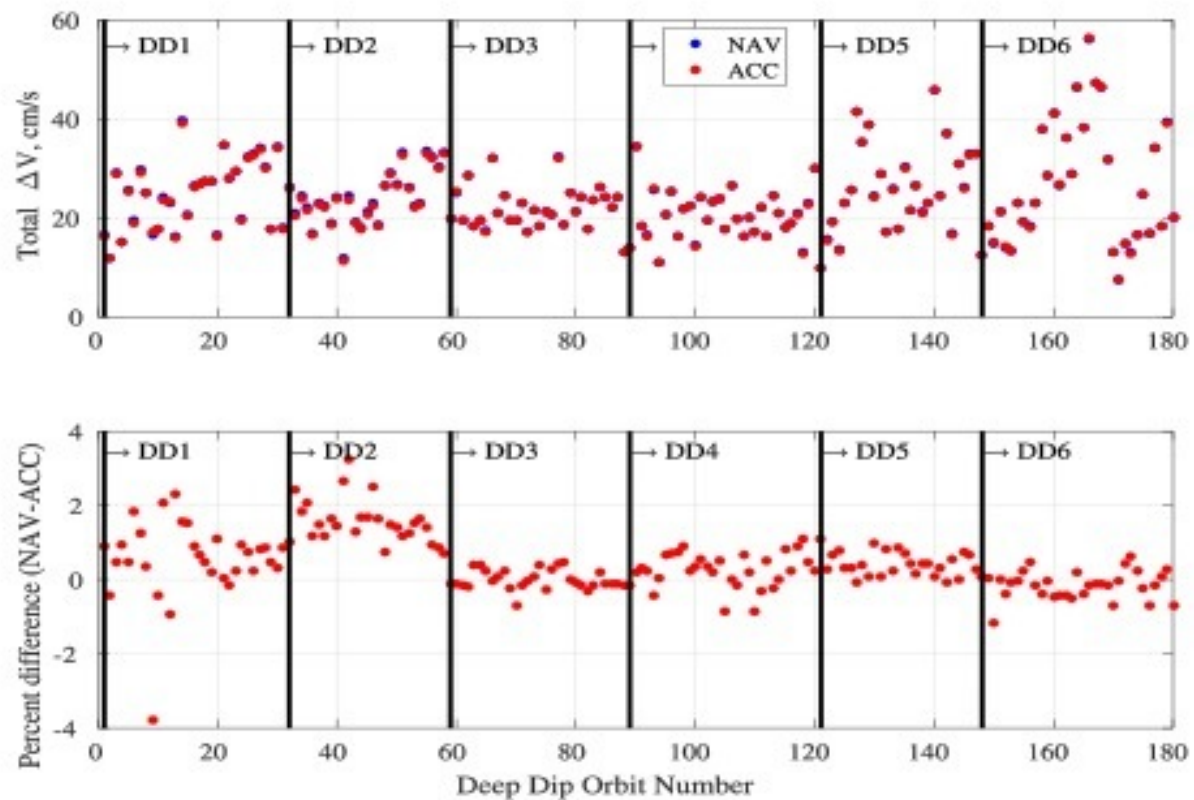

2016JA023641-f10-z-.jpg

This article is protected by copyright. All rights reserved. 


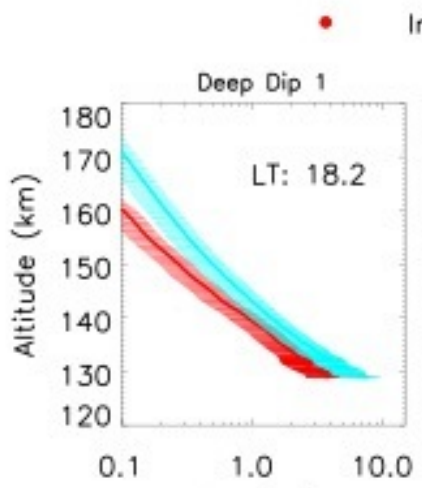

Ingress $\mathrm{ACC} \quad \mathrm{M}-\mathrm{GITM}$ Ingress
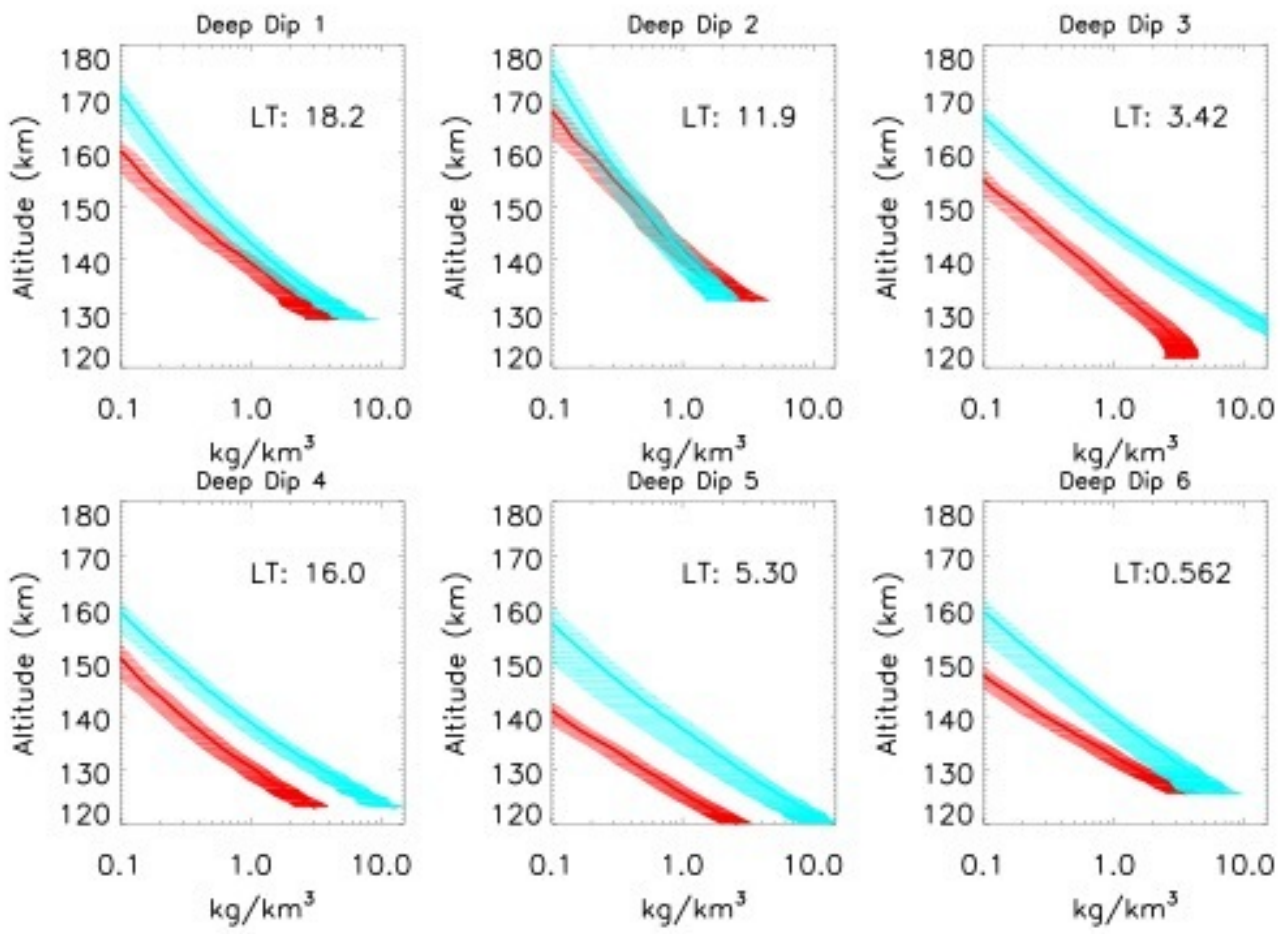

2016JA023641-f11-z-.jpg

This article is protected by copyright. All rights reserved. 

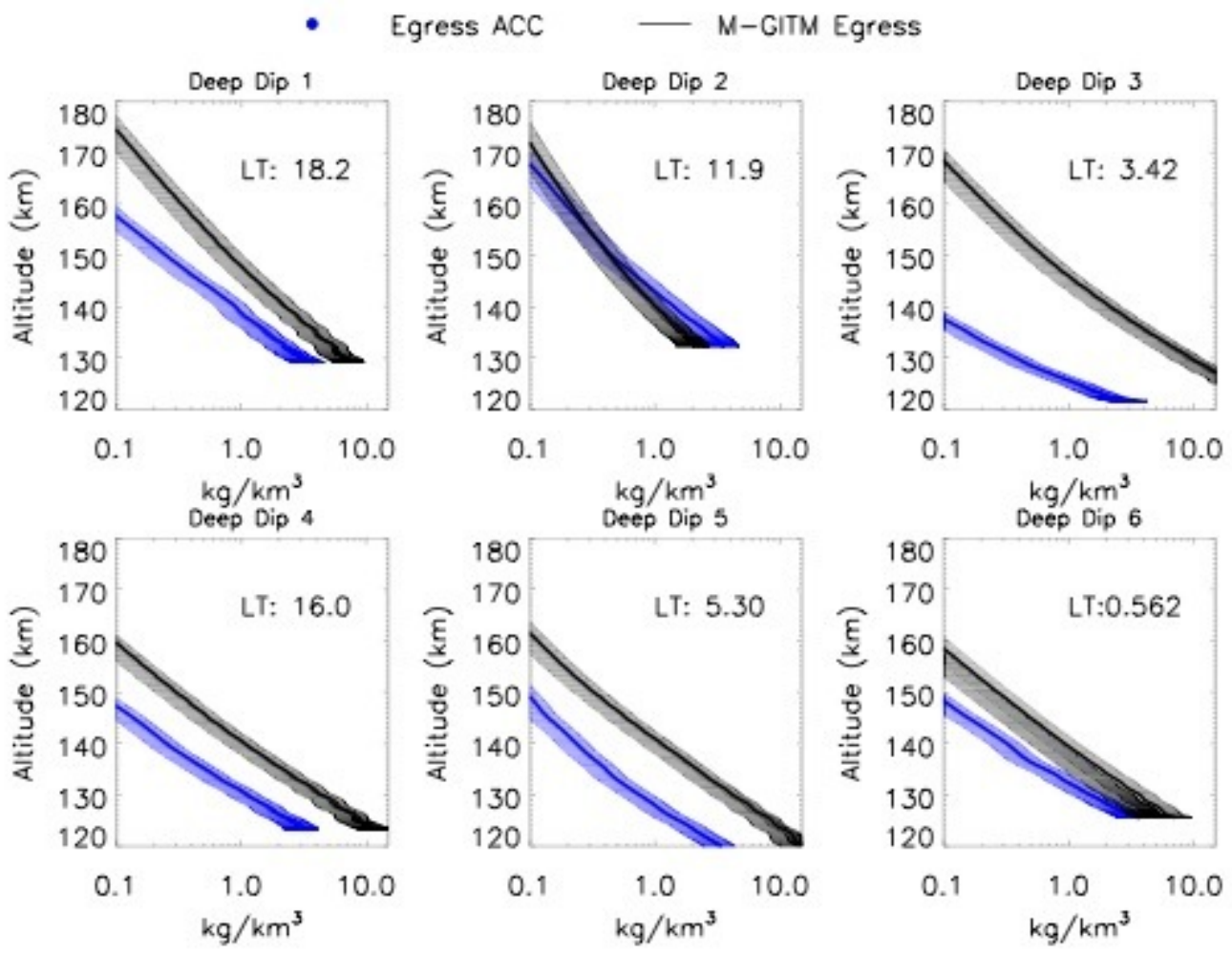

2016JA023641-f12-z-.jpg

This article is protected by copyright. All rights reserved. 